\title{
The Auditory English Lexicon Project: A multi-talker, multi-region psycholinguistic database of 10,170 spoken words and nonwords
}

\author{
Winston D. Goh ${ }^{1} \cdot$ Melvin J. Yap ${ }^{1} \cdot$ Qian Wen Chee ${ }^{1}$ \\ Published online: 14 April 2020 \\ (C) The Psychonomic Society, Inc. 2020
}

\begin{abstract}
The Auditory English Lexicon Project (AELP) is a multi-talker, multi-region psycholinguistic database of 10,170 spoken words and 10,170 spoken nonwords. Six tokens of each stimulus were recorded as 44.1-kHz, 16-bit, mono WAV files by native speakers of American, British, and Singapore English, with one from each gender. Intelligibility norms, as determined by average identification scores and confidence ratings from between 15 and 20 responses per token, were obtained from 561 participants. Auditory lexical decision accuracies and latencies, with between 25 and 36 responses per token, were obtained from 438 participants. The database also includes a variety of lexico-semantic variables and structural indices for the words and nonwords, as well as participants' individual difference measures such as age, gender, language background, and proficiency. Taken together, there are a total of 122,040 sound files and over 4 million behavioral data points in the AELP. We describe some of the characteristics of this database. This resource is freely available from a website (https://inetapps.nus.edu.sg/aelp/) hosted by the Department of Psychology at the National University of Singapore.
\end{abstract}

Keywords Speech database $\cdot$ Megastudy $\cdot$ Spoken word recognition $\cdot$ Auditory lexical decision $\cdot$ Psycholinguistics

The ease with which people are able to recognize printed and spoken words is one of the most impressive and important things humans do. Consequently, the processes underlying

This research was supported by Singapore Ministry of Education Academic Research Fund Tier-2 Grant MOE2016-T2-2-079, and the National University of Singapore Humanities and Social Sciences Seed Fund R-581-000-164-646, awarded to W.D.G. and M.J.Y.

We thank Keng Ji Chow for programming assistance, Sean Yap for web development, Jia Jun Ang, Mae Ang, Claire Chan, Magdalene Choo, Keng Ji Chow, Joyce Gan, Sydney Goh, Mabel Lau, Marcia Lee, Marcus Leong, Marissa Ng, Melvin Ng, Alvin Ong, Nigel Ong, Muhammad Nabil Syukri bin Sachiman, Si Ying Fong, Sze Ming Song, Jonathan Tan, Luuan-Chin Tan, Rong Ying Tan, Wei Yun Tan, Yin Lin Tan, Gareth Ting, Devni Wijayaratne, Chin Yi Wong, Taffy Yap, and Maisarah bte Zulkifli for audio recording, sound file processing, data acquisition, and processing.

We also thank Marc Brysbaert, Howard Nusbaum, David Pisoni, and Chris Westbury for permission to include their metrics on the website, and three anonymous reviewers for helpful comments.

Electronic supplementary material The online version of this article (https://doi.org/10.3758/s13428-020-01352-0) contains supplementary material, which is available to authorized users.

Winston D. Goh

psygohw@nus.edu.sg

1 Department of Psychology, National University of Singapore, Singapore 117570, Singapore isolated word recognition and processing have been extensively studied (Balota, Yap, \& Cortese, 2006; Dahan \& Magnuson, 2006). Words are also one of the most commonly used set of stimuli in cognitive and experimental psychology (Balota et al., 2007). Researchers have accumulated a great deal of information regarding how the different statistical properties of words (e.g., frequency of occurrence, imageability, number of letters or phonemes) influence how quickly and accurately people can recognize words, and how they influence other cognitive processes, such as memory.

However, the overwhelming majority of experiments that have used word stimuli have focused on the processing of printed words. From a methodological point of view, the development and presentation of spoken, compared to printed, word stimuli is far more labor-intensive and complex. For example, each auditory token has to be recorded by one or more speakers, the sound file has to be edited to isolate the word, normalized, and tested for intelligibility before it can be used. In this light, it is perhaps unsurprising that empirical and theoretical developments in visual, compared to auditory, word recognition research have been relatively more rapid and extensive (see also Tucker, Brenner, Danielson, Kelley, Nenadić, \& Sims, 2019). It is worth noting that Balota et al.'s (2007) English Lexicon Project's (ELP) behavioral and descriptive repository of visual word recognition data has contributed to these developments. 
This paper describes the Auditory English Lexicon Project (AELP), which was conceived to address the above constraints by developing a very large and well-characterized set of auditory word and nonword tokens that have been rigorously normed for intelligibility. These tokens are freely available to the research community via a webpage (https:// inetapps.nus.edu.sg/aelp/), and can be used for any experiment involving the presentation of spoken words and/ or nonwords. In the following sections, we provide a brief overview of the theoretical importance of auditory word processing for understanding cognitive processes, existing spoken word databases, the megastudy approach and recent auditory megastudies, before turning to the AELP.

\section{Auditory word processing}

Listening and reading essentially have the same goal - retrieving the meaning of the stimulus, but effects do not always generalize across modalities, suggesting that there may be fundamental differences in the underlying mechanisms for lexical processing depending on the medium. For example, spoken word processing is consistently slowed down by dense phonological neighborhoods, but orthographic neighborhoods exert inconsistent effects in visual word recognition (Andrews, 1997). Semantic richness effects, the general finding that words with richer semantic representations facilitate processing (Pexman, 2012), have been shown to be smaller in auditory compared to visual word recognition (Goh, Yap, Lau, $\mathrm{Ng}$, \& Tan, 2016). These dissociations between visual and spoken word recognition point to the possibility that the recognition process in speech may focus more on resolving phonological similarities first (Goh, Suárez, Yap, \& Tan, 2009; Luce \& Pisoni, 1998), and so any advantages from semantically richer words are attenuated in the face of greater wordform competition.

Research has also shown that speech perception may be a talker-contingent process (Nygaard, Sommers, \& Pisoni, 1994), and that indexical properties of spoken words - gender, accent, and other unique aspects of the talker's voice - are encoded and retained in memory (Goh, 2005; Goldinger, 1996b). Talker variability in the input enhances perceptual learning and word recognition in both adults (Logan, Lively, \& Pisoni, 1991; Pisoni \& Lively, 1995) and infants (Singh, 2008). These findings implicate the encoding of indexical information in long-term memory and provide support for an episodic mental lexicon (Goldinger, 1998).

In other cognitive domains, there is a well-known auditory advantage in the short-term memory (STM) literature, with several findings implicating the primacy of auditory codes in STM. For example, better memory for auditory compared to visually presented lists, especially in the primacy region, or the modality effect (Crowder, 1971; Penny, 1989); attenuation of the recency effect if an irrelevant speech sound is played at the end of list presentation, or the suffix effect (Crowder \& Morton, 1969); and fewer false memories for auditory versus visually presented lists of semantic associates (Olszewska, Reuter-Lorenz, Munier, \& Bendler, 2015) but the reverse for phonological associates (Lim \& Goh, 2019).

These selected examples highlight some of the important findings that differentiate studies using auditory versus visual stimuli, and studies using auditory tokens produced by multiple talkers. They point to the utility of having a large and easily accessible database of auditory tokens for experimental research.

\section{Spoken word databases}

As noted earlier, a significant bottleneck in auditory word recognition research has to do with the difficulty of developing auditory stimuli. The vast majority of existing speech databases comprise recordings of sentences, connected speech, and dialogue (e.g., TIMIT Acoustic-Phonetic Continuous Speech Corpus - Garofolo et al., 1993; The British National Corpus, 2007). These are generally not suitable for research using isolated spoken words. Some large isolated word databases tend to be tied to very specific contexts (e.g., 3000 names of Japanese railroad stations - Makino, Abe, \& Kido, 1988). Hence, many researchers using auditory tokens prepare their own stimuli from scratch for most new studies.

In 2014, at the initial stages of the current project, there were no large spoken word databases readily available. Since then, three have been published and are summarized in Table 1.

Due to the time-consuming nature of creating large speech databases, it is unsurprising that all of these have a single talker recording a large number of tokens. Older collections tend to have many talkers saying a handful of words or sentences (e.g., the TIMIT corpus had recordings of 630 talkers speaking ten sentences each). The largest multi-talker database of English isolated spoken words thus far is the PB/ MRT Word Multi-Talker Speech Database developed by the Speech Research Laboratory at Indiana University, comprising 450 words taken from phonetically balanced lists (IEEE, 1969) and the modified rhyme test (House, Williams, Hecker, \& Kryter, 1965), and tokens of each word spoken by 20 American English talkers: ten male and ten female. To our knowledge, there is currently no multi-talker database of spoken nonword stimuli.

\section{Auditory megastudies}

Most insights on the nature of auditory word processing have come from factorial designs in which lexical and other 


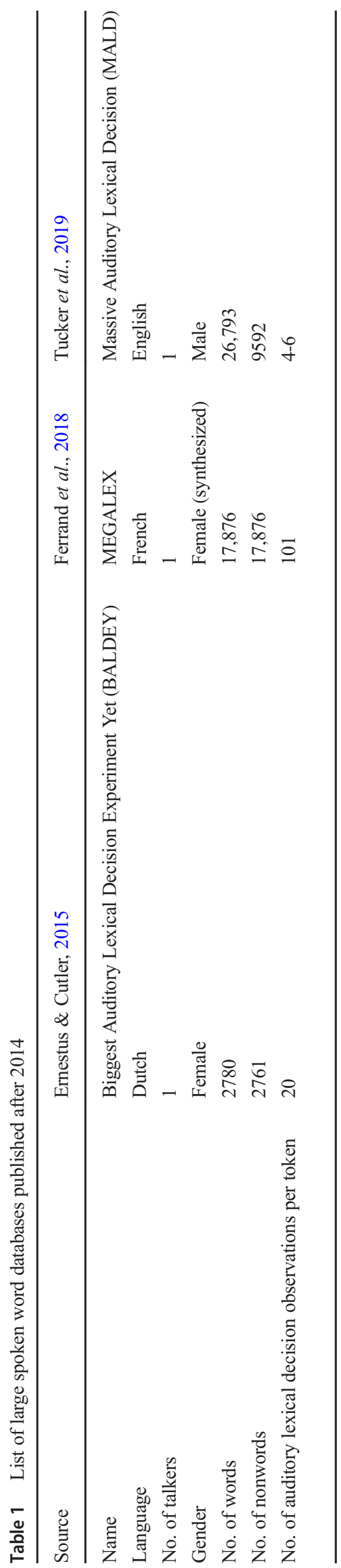

variables of interest were manipulated while other properties were held constant. As more lexical properties were shown to affect spoken word recognition from standard factorial designs, it has become increasingly challenging to manipulate a single property while keeping others constant, and at the same time ensuring an adequate number of stimuli within each cell (Cutler, 1981). Turning continuous psycholinguistic variables into categorical variables (a prerequisite for factorial experimental designs) may also spuriously magnify or diminish the influence of variables and lessen the likelihood of detecting non-linear relationships (Balota, Yap, Hutchison, $\&$ Cortese, 2012).

This has precipitated a complementary research approach called the megastudy approach (Balota, Cortese, SergentMarshall, Spieler, \& Yap, 2004), where researchers allow the language to define the stimuli, rather than selecting stimuli based on a limited set of criteria. Specifically, participants are presented with a large set of words, and recognition performance for these words is measured. Statistical techniques are then used to estimate the unique influence of different targeted variables, while controlling for correlated variables. The megastudy approach has catalyzed the development of many large-scale databases across different languages (e.g., French, Spanish, Dutch, Malay, Chinese) and has also generated many productive lines of research in the visual modality, with the empirical findings critical for informing and constraining theories and models of reading and reading development (see Balota et al., 2012, for a review).

In the auditory domain, this megastudy approach has begun to be used, primarily with the lexical decision task (LDT), where participants have to discriminate between real words and pronounceable nonwords (e.g., flirp). The number of responses collected for each stimulus in auditory megastudies have ranged from 101 (MEGALEX) to 20 (BALDEY), and 46 (MALD). MEGALEX and BALDEY had participants listen to all stimuli in approximately 50 and ten sessions, respectively. MALD had a variable number of responses per token as listeners listened to 400 words and 400 nonwords in each session, and were allowed to participate up to a maximum of three such sessions (with different tokens) if they wanted to.

\section{The Auditory English Lexicon Project}

The AELP had three key objectives. First and foremost, we aimed to create a large database of spoken English words and nonwords that would be beneficial to all researchers requiring spoken word stimuli. To maximize its utility, the AELP was designed to be a multi-talker, multi-region database. It included six instances of each stimulus, as spoken by native speakers of American, British, and Singapore English, with one from each gender. The first two sets of talkers covered the world's two largest populations of native English speakers. 
Second, it aimed to provide intelligibility norms for all tokens. Most spoken word recognition studies typically report that only tokens with some level of intelligibility (e.g., correctly identified by $80 \%$ of listeners) are used. None of the previous auditory megastudies have published any intelligibility scores for their tokens; only the accuracy rates in auditory lexical decision (ALD) were available. However, ALD accuracy data only indicate whether the token was perceived as a word, and not what word was heard. It is important to know what the correct identification rate for a spoken word is as it is possible that one word may be misheard for another. For example, bag may be misheard as beg, or vice-versa, but in both cases a participant would classify it as a word in an LDT, and would be scored as correct. However, the properties of the two words will differ (e.g., one is concrete and the other is abstract) and, depending on the intended target, the wrong properties may be used for subsequent experimental manipulation or analysis. Similarly, if a nonword is consistently heard as a word, it may not be a useful token to use in an experiment.

The third aim was to determine the robustness of word property effects for varieties of the same language across different talkers in ALD. All auditory megastudies have thus far been based on a single talker, and the extent to which effects can generalize across talkers, regions, and gender remains unknown.

The next section describes the stimuli selection considerations and summarizes the variables included in the database. The following two sections - Word recording and Word identification - describe the methodologies and results specific to the first two aims. These two phases of the project served to iteratively record the stimuli and test their intelligibility in order to finalize the list of tokens to be included in the database. The section on Word recognition will describe the behavioral data that are available and addresses the third aim. All protocols were approved by the National University of Singapore (NUS) Institutional Review Board. The final sections will describe some analyses and examples of how the data may be used, and a brief overview of the features of the website.

\section{Stimulus selection}

\section{Words}

The goal of the AELP was to maximize the utility of the word stimuli for as many researchers as possible. Two general principles were adopted to achieve this: one, the words must be familiar to most people, and two, the words should have values or ratings on as many psycholinguistic variables and word properties that are currently available in the literature.

Although printed word frequency and subjective familiarity ratings covary, the latter has been shown to be a more reliable predictor of lexical decision performance (e.g., Gernsbacher, 1984; Kreuz, 1987). To the best of our knowledge, the largest database of subjective familiarity (FAM) ratings thus far is Nusbaum, Pisoni, and Davis' (1984) Hoosier Mental Lexicon (HML), which collected ratings for 19,750 words from the intersection of Merriam-Webster's Pocket Dictionary and Webster's Seventh Collegiate Dictionary. Each word's FAM score was derived from averaging $12 \mathrm{ob}-$ servations, based on a seven-point scale, where a rating of 1 indicated an unknown word, a 4 indicated that the rater knew the stimulus was a word, but did not know the meaning, and a 7 indicated that the word was recognized with at least one meaning known. The other points represented intermediate levels of familiarity (the full rating scale is listed in Appendix 1).

The aim was to have around 10,000 words in the AELP. Words with Hoosier FAM scores of at least 6.2 were selected to form the initial list of 10,446 words. We cross-checked this with words that had NUSFAM ${ }^{1}$ scores of at least 6 , and removed function words (e.g., am), and people's names. Several research assistants went through the list and highlighted unusual words (e.g., choler, clew), which were eventually dropped. All words not already included from the McRae, Cree, Seidenberg, and McNorgan (2005) number of features (NoF) norms were included in order to optimize the use of this semantic property. The final AELP database comprised 10,170 words $^{2}$.

\section{Nonwords}

Unique nonwords were created and yoked to each word in the database so that they resembled the target word as closely as possible. Although the WUGGY pseudoword generator (Keuleers \& Brysbaert, 2010) was developed to create orthographically rather than phonologically plausible words, it was used as an initial guide to list plausible candidates for selection or modification. We followed BALDEY's approach in ensuring that, as far as possible, the structure of the tokens became nonwords only towards the end of the phoneme sequence so that nonword detection cannot be strategically determined. Specifically, for words with three or more syllables, at least the first syllable was retained in its entirety (e.g., for the word orchestra / 'or, kEstra/, a WUGGY suggested nonword was orshistre, which was then modified to orchistro and transcribed as / 'or , kistroo/, thus retaining the first syllable of the

\footnotetext{
${ }^{1}$ At the time of stimulus selection, our laboratory had also collected FAM ratings for 6117 words with scores derived from 25-133 observations per word, for various research and student projects since 2002, using the same scale as the HML. This set of 6117 was used to cross-check the Hoosier FAM words. At the end of this project, NUSFAM grew to 12,163 words, including all words in the AELP.

${ }^{2}$ The final set included a few changes based on outcomes from the Word identification phases.
} 
target word and retaining two-thirds of the phonemes in the other syllables to derive the nonword).

It was more challenging to follow this principle for monosyllabic and disyllabic words. For both sets, we tried to retain the first phoneme of each syllable, in order to ensure that about one- to two-thirds of the target word's phonemes were retained. However, it was not always possible if all candidate nonwords were already yoked to other words (e.g., the nonword zoong $/ z u \eta /$ had to be yoked to the word earn $/ 2: n /$ ).

\section{Descriptive characteristics}

Tables 2 and 3 summarize the structural and lexico-semantic variables, respectively, that are included in the database. The descriptive statistics are included in Appendix 2.

Structural indices such as neighborhood density were computed separately for American and British English. We used the Oxford Dictionaries (2019) Application Programming Interface $(\mathrm{API})^{3}$ to obtain International Phonetic Alphabet (IPA) ${ }^{4}$ transcriptions of 26,604 of the 40,481 ELP (Balota et al., 2007) words that had phonological transcriptions in both American and British English ${ }^{5}$. This base dataset is close in number to the 20,000 words in the HML, which has also been used to compute phonological indices in many previous studies (see Vitevitch, 2008) and so would allow a similar base for comparison of the indices with previous work. The structural properties of the 10,170 AELP words and nonwords were computed with reference to the 26,604 base dataset, which is included in the supplemental material.

Table 4 summarizes the correlations between some of the structural phonological properties for words and nonwords, and indicates that the nonwords resemble the yoked words closely and share similar properties, as intended.

From Table 19 in Appendix 2, most of the words in the AELP have the relevant measures from other large databases, ranging from 75\% (7612/10170) for the Warriner et al. (2013) affective norms to $98 \%(10012 / 10170)$ for the Brysbaert et al. (2019) prevalence norms. We then checked the extent to which other well characterized lists of words that have been used extensively in the field are found in the AELP database

\footnotetext{
${ }^{3}$ As Oxford Dictionaries declined permission, we are unable to include the words' phonological transcriptions in the database. Nonetheless, interested researchers are able to request free researcher API access from Oxford Dictionaries, and we have included the annotated Python code used to retrieve the transcriptions in the supplemental material.

${ }^{4}$ A description of the IPA symbols used by Oxford Dictionaries is available at https://public.oed.com/how-to-use-the-oed/key-to-pronunciation/ (retrieved 16 October 2019).

5 A dictionary for Singapore English is currently unavailable at Oxford Dictionaries. Users who want estimates of Singapore English should use the British metrics. The pronunciation of Standard Singapore English, which is the variety used by our Singaporean talkers, is closer to British than American English (e.g., ask is pronounced /a:sk/ and not /æsk/; car is pronounced /ka:/ and not $/ \mathrm{kar} /$ ), and spelling follows British conventions (see Deterding, 2007; Leimbgruber, 2011; Tay \& Gupta, 1983).
}

(Table 5). From both Tables 5 and 19, it can be seen that the AELP database should have enough words to be an optimal resource for selecting auditory experimental stimuli in psycholinguistic and cognitive studies.

\section{Word Recording}

\section{Talker Selection}

Potential talkers were recruited from the NUS and wider expatriate communities. To minimize regional dialect differences for the American and British talkers, we considered only those who grew up (for the first 18 years of their lives) in the mid-western states of the United States (for American talkers) or in the Home Counties (for British talkers). Experience with and the ability to read the International Phonetic Alphabet (IPA) were also emphasized.

Fifteen participants were invited to an individual $1-\mathrm{h}$ trial recording session using the apparatus and procedures described in the next section, and were each reimbursed S\$10. A list of 80 words from Goh et al. (2016), for which intelligibility norms were available from that study, plus the corresponding yoked nonwords from the AELP, was used in the trial session. For each of the seven participants with the clearest recordings and who could potentially serve as talkers, their 80 word and 80 nonword tokens were presented to seven different groups of 15-20 undergraduate NUS students each for intelligibility testing (details are described in the Word identification section). All seven potential talkers exceeded the average correct identification (ID) rate of $.76^{6}$ for the same 80 words from Goh et al. (2016), but we dropped one female Singapore English speaker to form the final six AELP talkers, whose characteristics are summarized in Table 6.

\section{Recording and editing procedures}

All recordings were done in a bespoke sound isolation booth with a Field Sound Transmission Class (FSTC) 56 rating. Speech signals were captured with an Audio-Technica ATM75 cardioid condenser head-mounted microphone connected to a Pentax Computerized Speech Lab (CSL) Model 4500 voice recorder, and saved as 16 -bit mono, $44,100-\mathrm{Hz}$ .wav sound files.

\footnotetext{
${ }^{6}$ This rate is relatively low as we deliberately chose several words in the list of 80 that had low ID scores, e.g., colander, ID $=.23$, in order to see if the potential talkers could be clearer than the one used in the earlier study. The average ID rate for all words for the talker in Goh et al. (2016) is much higher at .94 .
} 


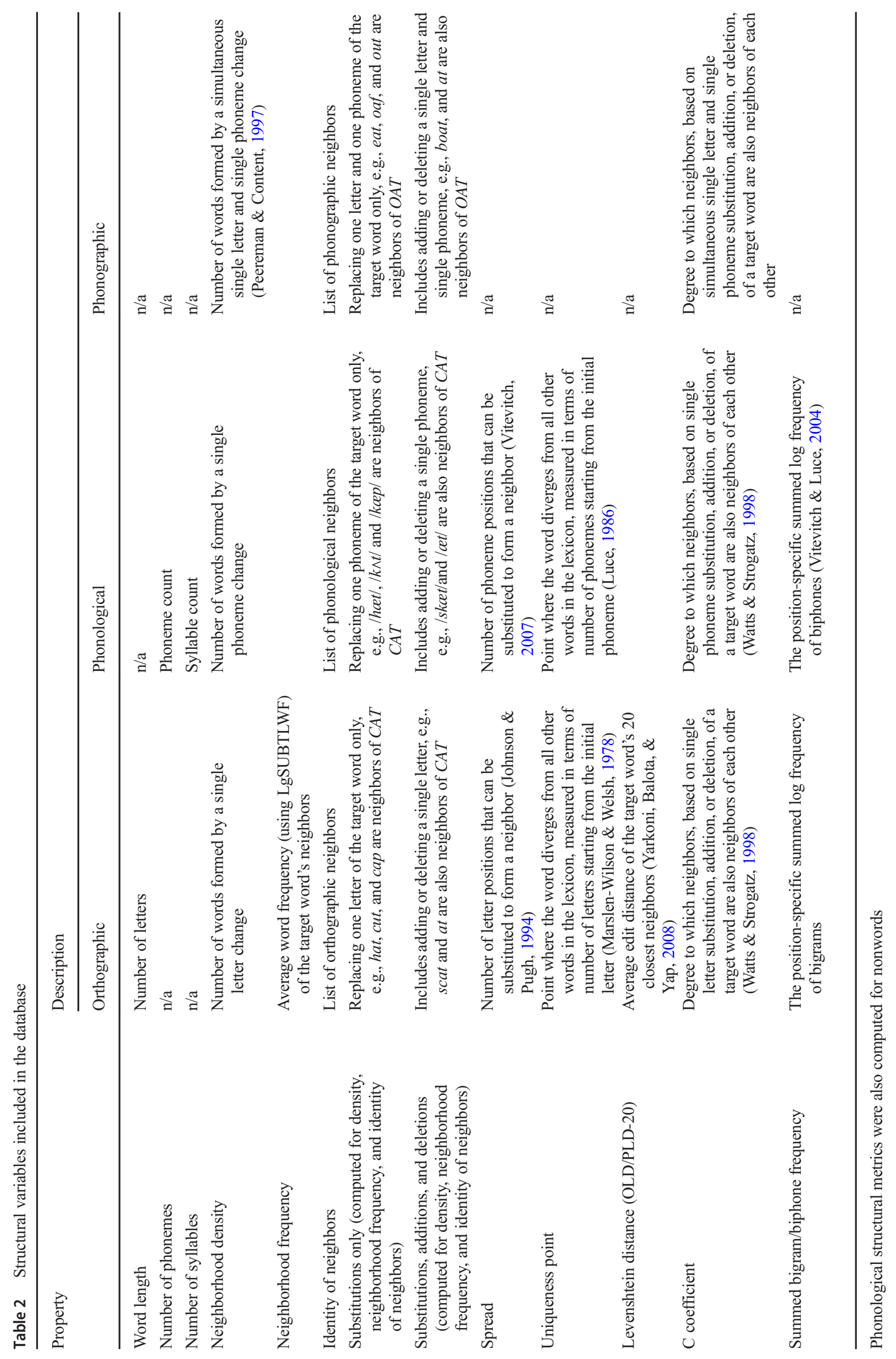


Table 3 Lexico-semantic variables included in the database

\begin{tabular}{|c|c|}
\hline Property & Description \\
\hline Number of morphemes & Number of meaningful units within a word \\
\hline $\begin{array}{l}\text { Part of speech (POS): adjective, determiner, } \\
\text { noun, pronoun, adverb, interjection, } \\
\text { number, verb, conjunction, name, } \\
\text { preposition }\end{array}$ & Based on the SUBTLEX databases \\
\hline Word frequency & $\begin{array}{l}\text { Log-transformed subtitle word frequency } \\
\text { estimates (Brysbaert \& New, 2009) }\end{array}$ \\
\hline Contextual diversity & $\begin{array}{l}\text { Log subtitle contextual diversity estimates } \\
\text { (Brysbaert \& New, 2009) }\end{array}$ \\
\hline Familiarity (FAM) & Average subjective familiarity ratings \\
\hline NUS FAM & From National University of Singapore students \\
\hline Hoosier FAM & $\begin{array}{l}\text { From Indiana University students (Nusbaum } \\
\text { et al., 1984) }\end{array}$ \\
\hline Word prevalence & $\begin{array}{l}\text { Estimates of the number of people who know } \\
\text { the word (Brysbaert, Mandera, McCormick, } \\
\text { \& Keuleers, 2019) }\end{array}$ \\
\hline \multicolumn{2}{|l|}{ Prevalence } \\
\hline \multicolumn{2}{|l|}{ Percentage known } \\
\hline Concreteness rating & $\begin{array}{l}\text { Measure of word concreteness (Brysbaert, } \\
\text { Wariner, \& Kuperman, 2014) }\end{array}$ \\
\hline Age of acquisition (AoA) & $\begin{array}{l}\text { Index of age when the word is acquired } \\
\text { (Kuperman, Stadthagen-Gonzalez, \& } \\
\text { Brysbaert, 2012) }\end{array}$ \\
\hline Semantic neighborhood density (SND) & $\begin{array}{l}\text { Measures of semantic neighborhood density } \\
\text { (Shaoul \& Westbury, 2010) }\end{array}$ \\
\hline Neighbor count (Ncount) & $\begin{array}{l}\text { Number of neighbors within a pre-specified } \\
\text { neighborhood threshold }\end{array}$ \\
\hline Average radius of co-occurrence (ARC) & $\begin{array}{l}\text { Mean distance between target word and its neighbors } \\
\text { within a pre-specified neighborhood threshold }\end{array}$ \\
\hline Affective ratings & $\begin{array}{l}\text { Average subjective ratings of affect (Warriner, } \\
\text { Kuperman, \& Brysbaert, 2013) }\end{array}$ \\
\hline Valence & $\begin{array}{l}\text { How pleasant the word is (Osgood, Suci, \& } \\
\text { Tannenbaum, 1957) }\end{array}$ \\
\hline Arousal & $\begin{array}{l}\text { Degree to which the word evokes arousal } \\
\text { (Osgood et al., 1957) }\end{array}$ \\
\hline Dominance & $\begin{array}{l}\text { Extent to which the word denotes weakness/ } \\
\text { submissiveness or strength/dominance } \\
\text { (Osgood et al., 1957) }\end{array}$ \\
\hline
\end{tabular}

The words and nonwords, excluding the 80 words and 80 nonwords already recorded in the trial recording sessions, were divided into 40 lists of 252 token-sets each ${ }^{7}$. A tokenset comprised a word and its corresponding nonword. The lists were equated on three lexical properties: the average logtransformed subtitle word frequency (LgSUBTLWF) from Brysbaert and New (2009), the average number of phonemes (N_Phon), and the average phonological Levenshtein distance (PLD20), which indexes the mean number of phoneme deletions, insertions, or substitutions required to transform a word

\footnotetext{
$\overline{7}$ The original intention was to have 10,160 words in the database. Some words were replaced eventually because of poor intelligibility and new words added for recording in the subsequent re-recording sessions.
}

into its 20 closest Levenshtein neighbours (Yarkoni et al., 2008), all $p$ values $>.19$. This was done to minimize between-list differences in potential pronunciation difficulty arising from frequency of use, word length, and word-form similarity, respectively.

For each token-set, the talker produced two utterances of the word with a pause between each utterance, followed by a similar two-utterance sequence for the nonword, aided by its IPA transcription. Each talker completed about 85 token-sets before the research assistant (RA) saved the sequence of utterances in a raw, uncut .wav file. Any mispronunciations or dysfluencies noted by the RAs, who were all trained in IPA phonetic notations, were re-recorded. One list could be recorded in an hour, with each talker recording for between two and 
Table 4 Correlations between words and nonwords' structural phonological properties

\begin{tabular}{lll}
\hline Property & American English & British English \\
\hline Number of phonemes & .97 & .97 \\
Number of syllables & .97 & .99 \\
Neighborhood density & .73 & .75 \\
$\quad$ (substitution, addition, & & \\
$\quad$ and deletion) & .88 & .90 \\
PLD20 & .88 & \\
\hline
\end{tabular}

four hours per session, with multiple breaks as needed. Talkers were reimbursed S\$60 for every 1000 token-sets, and a completion bonus of $\mathrm{S} \$ 400$ was provided when all tokens were recorded. All talkers completed the full set of recordings in 11 to 16 sessions. For re-recordings after the ID phases, the talkers were reimbursed at the same rate as above, but without the completion bonus.

Adobe Audition was used to edit the raw recordings to be saved as individual .wav files for each of the utterances. All tokens were then digitally levelled to approximately $70 \mathrm{~dB}$ to ensure that all tokens had the same total root-mean-square amplitude using the match loudness function in Audition. RAs then indicated which of the two instances of each token was better, based on enunciation, noise, and realization of vowels. The better token was subsequently used in the ID phases.

\section{Word identification}

This phase of the project served to determine the intelligibility of the selected tokens and whether re-recordings were required for some items. Tokens that did not achieve an ID rate of at least .75 were re-recorded (or changed). The new tokens were then subjected to another round of intelligibility testing.

\section{Materials}

The first round of word ID (WordID1) comprised the 80 token sets (words and nonwords) from the trial recording sessions. The second round (WordID2) included the remaining 10,080 token-sets. This was divided into 30 lists $^{8}$ of 336 token-sets and grouped into six groups of five lists each, with all lists and groups equated on the three lexical properties for the words as in the recording sessions, all $F_{\mathrm{S}}<1$. The third round (WordID3) comprised re-recordings of tokens that failed to achieve the ID criterion in both WordID1 and WordID2,

\footnotetext{
${ }^{8}$ Talker F1's WordID2 was based on the 40 lists from the main recording session, but most participants were able to complete a list of 504 tokens ( 252 words and corresponding nonwords) in $30-40$ minutes in one session, and so we decided to increase the number of tokens in one session for the remaining talkers
}

which varied between $10.24 \%$ and $11.66 \%$ of tokens across talkers, and were divided into three lists of varying numbers of tokens. This round also included testing of some new nonwords and words for possible replacement of tokens that had consistently poor ID rates.

\section{Participants}

The goal was to have each token tested by between 15 and 20 different participants. A total of 561 participants from the NUS community took part in one or more rounds of the identification phase. It was ensured that no participant heard each token more than once within or across talkers. In their first session, participants completed a language background questionnaire (LBQ) before the ID task, and the 40-item vocabulary subscale of the Shipley Institute of Living Scale (Shipley, 1940) at the end of the session.

Participants were reimbursed $\mathrm{S} \$ 5$ for every half-hour. WordID1 comprised a single half-hour session; WordID2 was run as cycles of five 1 -h sessions, with participants having an option of participating in more than one cycle; and WordID3 had three 1-h sessions. For WordID2, adapting from MEGALEX's completion incentive, participants were given a S\$25 bonus for every five sessions completed; and adapting from MEGALEX's continuation criterion, participants were also told that they would be dropped from further sessions if their accuracy rate dropped below $80 \%$ for two consecutive sessions.

Table 7 summarizes the profile of the participants. All participants indicated English as their first language, reported no speech or hearing disorder, and had lived in Singapore for more than half their lives.

\section{Procedure}

Participants were tested in groups of 12 or fewer on individual PCs running E-prime (Schneider, Eschman, \& Zuccolotto, 2002). On each trial, an auditory token was binaurally presented via beyerdynamic DT150 headphones at approximately 70 dB SPL. Participants were instructed to make a judgment on whether what they heard was a word or nonword. For words, participants had to spell out the word using the keyboard; for nonwords, they typed an " $x$ ". They pressed the ENTER key to submit the trial response, after which they were asked to rate the confidence of their response on a nine-point Likert scale, with higher numbers representing greater confidence. Pressing a number initiated the next trial after a 100-ms blank screen.

For the multi-session cycles in Word ID2, each 1-h session was done approximately 1 week apart. One list was presented in each session and word and nonword tokens were randomly interspersed for each participant. A balanced latin-square was used to rotate the order of lists within each cycle across the 
Table 5 Proportion of AELP words with measures from smaller word property databases

\begin{tabular}{lllll}
\hline Property & Source & $\begin{array}{l}\text { No. of words } \\
\text { in source }\end{array}$ & $\begin{array}{l}\text { No. of words } \\
\text { in AELP }\end{array}$ & $\begin{array}{l}\text { Percent of source } \\
\text { in AELP (\%) }\end{array}$ \\
\hline Imageability & Cortese \& Fugett (2004) & 6277 & 4776 & 76.09 \\
Imageability & Schock, Cortese, \& Khanna (2012) & 3000 & 2272 & 75.73 \\
Number of features (NoF) & McRae et al. (2005) & 541 & 491 & 90.76 \\
Phonological false memory associates & Sommers \& Lewis (1999) & 744 & 552 & 74.91 \\
Semantic false memory associates & $\begin{array}{l}\text { Roediger, Watson, McDermott, } \\
\text { \& Gallo (2001) }\end{array}$ & 825 & & 735.09 \\
\hline
\end{tabular}

sessions. A similar procedure was used for the rounds in WordID3. Participants were given a break every 75-90 trials in each session of WordID2 and WordID3. There was one break after 80 trials for WordID1. Participants were debriefed at the end of their last session.

\section{Scoring}

For words, all incorrect responses that were automatically flagged by E-prime based on spelling accuracy were checked to see if they could be considered correct. For example, obvious spelling errors (occurrence spelt as occurence), typographical errors involving adjacent letters on the keyboard (violin spelt as violim), British/ American spelling variants (colour spelt as color), and homophone responses (sail spelt as sale), were all rescored as correct for the purposes of estimating ID rates $^{9}$. For nonwords, all incorrect responses were checked to see if any nonword was consistently perceived to be a word (e.g., $\mid$ t $\partial \mathrm{p} / \mathrm{w}$ was heard as chop). These were either re-recorded or a new nonword was recorded and tested again.

At the end of WordID3, all tokens were finalized regardless of their ID rate. For tokens that went through two rounds of testing (WordID1/WordID2 and WordID3), the token with the better ID was kept in the database. Table 8 summarizes the average ID and confidence rates for the talkers, and Table 9 depicts the correlations between the ID rates for each talker. The relatively high intercorrelations attest to the high reliability of the intelligibility measure (Keuleers, Lacey, Rastle, \& Brysbaert, 2012) and reflect the amount of item-level variance that can be explained in these datasets (Courrieu \& Rey, 2011).

Figure 1 depicts the proportion of tokens across different ID rates among the six talkers. The results show that the vast majority of tokens (over $86 \%$ ) have an ID score of at least .8, indicating that the AELP database comprises highly intelligible tokens that can be used in experiments.

\footnotetext{
${ }^{9}$ Individual homophone ID rates are described in Appendix 4.
}

\section{Word recognition}

This phase of the project collected latency and accuracy data for auditory lexical decision for all tokens and talkers.

\section{Materials}

The AELP words were divided into 15 lists of 678 token-sets and grouped into three groups of five lists each, with all lists and groups equated on the three lexical properties for the words as in the recording sessions, all $F_{\mathrm{S}}<1$.

\section{Participants}

The goal was to have each token tested by between 25 and 36 different participants. Four hundred and thirtyeight participants from the NUS community took part and it was ensured that no participant heard each token more than once within or across talkers. As in the ID phase, in their first session, participants completed a language background questionnaire (LBQ) before the LDT. This time, we replaced the Shipley (1940) subscale with a newer 60-item subset of a vocabulary test (Levy, Bullinaria \& McCormick, 2017) and a 60-item spelling test (Burt \& Tate, 2002) at the end of the first session.

Table 6 Talker characteristics

\begin{tabular}{llll}
\hline Talker code & $\begin{array}{l}\text { English } \\
\text { variety }\end{array}$ & $\begin{array}{l}\text { Age at time of } \\
\text { recording }\end{array}$ & $\begin{array}{l}\text { Region grew up in } \\
\text { for first 18 years }\end{array}$ \\
\hline Female & Singapore & 22 & Singapore \\
F1 & American & 21 & Minnesota \\
F2 & British & 38 & Surrey \\
F3 & Singapore & 27 & \\
Male & American & 21 & Singapore \\
M1 & British & 37 & Wisconsin \\
M2 & & & Essex \\
M3 & &
\end{tabular}


Table 7 WordID participant profile

\begin{tabular}{|c|c|c|c|c|}
\hline & \multicolumn{2}{|c|}{ Female $(n=391)$} & \multicolumn{2}{|c|}{ Male $(n=170)$} \\
\hline & $M$ & $S D$ & $M$ & $S D$ \\
\hline Age & 20.60 & 1.34 & 22.42 & 1.41 \\
\hline Vocabulary score & 30.26 & 3.38 & 32.07 & 3.33 \\
\hline
\end{tabular}

Most (44.92\%) participants completed five sessions of WordID2. $21.03 \%$ completed ten sessions, $5.35 \%$ completed 15 sessions, $0.89 \%$ completed 20 sessions, and $0.89 \%$ completed 25 sessions; $12.48 \%$ took part only in WordID1 and $14.44 \%$ took part only in WordID3

Similar to the ID phase, participants were reimbursed $\mathrm{S} \$ 5$ for every half-hour and a $\mathrm{S} \$ 25$ bonus for every five sessions completed. The same continuation criterion was adopted; participants were told that they would be dropped from further sessions if their accuracy rate dropped below $80 \%$ for two consecutive sessions.

Table 10 summarizes the profile of the participants. All participants indicated English as their first language, reported no speech or hearing disorder, and had lived in Singapore for more than half their lives. Other language details can be found in Appendix 4.

\section{Procedure}

Participants were tested in groups of 12 or fewer on individual PCs running E-prime with the Chronos response box (Schneider, Eschman, \& Zuccolotto, 2012) that had the leftmost and rightmost buttons labelled "nonword" and "word" respectively. On each trial, an auditory token was binaurally played via beyerdynamic DT150 headphones at approximately $70 \mathrm{~dB}$ SPL. Participants were asked to determine, as quickly and as accurately as possible, whether the token was a word or a nonword. Latency was measured from stimulus onset till the button press. An inter-stimulus-interval (ISI) of $200 \mathrm{~ms}$ elapsed before the next token was played. Participants were given a short break after every 113 trials.

Table 8 Intelligibility rates across talkers and stimuli

\begin{tabular}{|c|c|c|c|c|c|c|c|c|}
\hline \multirow{3}{*}{ Talker } & \multicolumn{4}{|c|}{ Word } & \multicolumn{4}{|c|}{ Nonword } \\
\hline & \multicolumn{2}{|l|}{ ID } & \multicolumn{2}{|c|}{ Confidence } & \multicolumn{2}{|l|}{ ID } & \multicolumn{2}{|c|}{ Confidence } \\
\hline & $M$ & $S D$ & $M$ & $S D$ & $M$ & $S D$ & $M$ & $S D$ \\
\hline $\mathrm{F} 1$ & .93 & .12 & 8.25 & 0.54 & .92 & .10 & 6.26 & 0.66 \\
\hline $\mathrm{F} 2$ & .92 & .13 & 8.18 & 0.58 & .93 & .12 & 6.41 & 0.63 \\
\hline F3 & .92 & .14 & 8.25 & 0.62 & .92 & .10 & 6.33 & 0.63 \\
\hline M1 & .92 & .14 & 8.13 & 0.64 & .94 & .10 & 6.34 & 0.55 \\
\hline M2 & .91 & .14 & 8.34 & 0.56 & .91 & .12 & 6.42 & 0.66 \\
\hline M3 & .92 & .13 & 8.26 & 0.61 & .93 & .10 & 6.36 & 0.60 \\
\hline
\end{tabular}

As in WordID, each 1-h session was done approximately 1 week apart. One list was presented in each session and word and nonword trials were randomly interspersed for each participant. A balanced latin-square was used to rotate the order of lists within each group across participants and sessions. Participants were debriefed at the end of their last session.

\section{Behavioral measures}

Response times (RT) were cleaned as follows. First, all inaccurate responses were removed $(10.64 \%$ for words, $8.40 \%$ nonwords). Next, RTs less than $200 \mathrm{~ms}$ and greater than $3000 \mathrm{~ms}$ were removed $(0.42 \%$ words, $0.85 \%$ nonwords). RTs that were greater or less than $2.5 \mathrm{SDs}$ from each individual participant's overall mean for that session were then removed (1.74\% words, $3.20 \%$ nonwords). We also computed a dependent measure that subtracted token duration from RT, which has been used in some previous studies (e.g., Luce \& Pisoni, 1998; Taft \& Hambly, 1986; see also Goldinger, 1996a).

All valid responses were then averaged for each item to obtain item-level measures for each talker. We also computed dialect-level estimates, which comprised trials averaged across both male and female talkers of the same dialect, using the same logic as described earlier. The behavioral measures available in the database are listed in Table 11. The descriptive statistics are summarized along with the durations of the finalized tokens in Appendix 3.

The correlations between talkers and dialects for zRT are summarized in Tables 12 and 13. The standardized item score is a more reliable measure of LDT performance as different sets of participants contributed RTs for different words, and the standardized score minimizes the influence of a participant's processing speed and variability (see Faust, Balota, Spieler, \& Ferraro, 1999). The full correlation matrix between behavioral measures and the structural and lexico-semantic properties can be found in the supplemental materials.

\section{Sample analyses and uses of the data}

\section{Intelligibility data}

Speech intelligibility has traditionally been studied using the perceptual identification task, where tokens are identified at different signal-to-noise ratios, using noise as a mask (see Pisoni, 1996), and seldom in the clear. Word frequency and familiarity facilitates, whereas similarity in lexical neighborhoods inhibits, correct identification in noise (e.g., Rosenzweig \& Postman, 1957; Treisman, 1978). We explored the influence of structural and lexical variables on our ID data, which was presented without noise, by performing a multiple regression for each talker with ID scores as the criterion and two measures of 
Table 9 Correlations between talker intelligibility rates for words (upper triangle) and nonwords (lower triangle)

\begin{tabular}{lllllll}
\hline Talker & F1 & F2 & F3 & M1 & M2 & M3 \\
\hline F1 & & .60 & .66 & .68 & .62 & .66 \\
F2 & .44 & & .68 & .67 & .72 & .66 \\
F3 & .42 & .51 & & .74 & .70 & .77 \\
M1 & .48 & .49 & .46 & & .69 & .73 \\
M2 & .46 & .63 & .49 & .49 & & .70 \\
M3 & .47 & .48 & .54 & .51 & .49 & \\
\hline
\end{tabular}

familiarity (NUSFAM and prevalence), two measures of phonological similarity (neighborhood density and PLD20), and a measure of word frequency (lgSUBTLCD) as predictors. The outcome is summarized in Table 14.
The results are highly consistent across talkers. More familiar and more frequently occurring words have higher intelligibility, while more phonologically confusable words (higher density and closer PLD20 distances) are associated with poorer intelligibility. These patterns indicate that although only high FAM words were included in the database, there is still enough range in the database to facilitate the exploration of lexical and other influences on behavioral outcomes.

\section{Auditory Lexical Decision Data}

Item-level regressions To determine whether the database could replicate some of the classic findings in the auditory lexical decision literature, such as word frequency facilitation (e.g., Taft \& Hambly, 1986) and phonological neighborhood
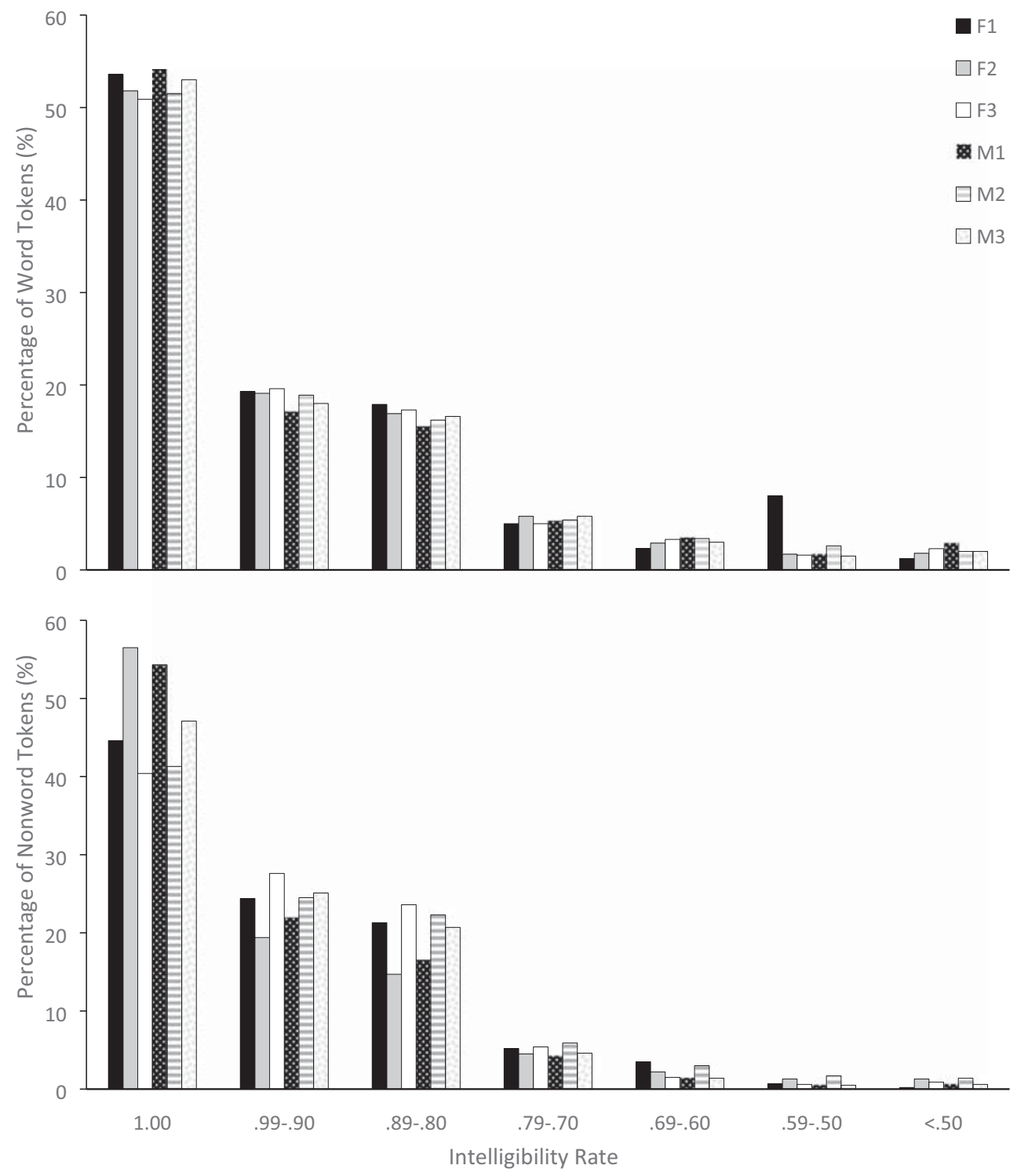

Fig. 1 Word (top panel) and nonword (bottom panel) ID rate percentages across talkers 
Table 10 Word recognition participant profile

\begin{tabular}{|c|c|c|c|c|}
\hline & \multicolumn{2}{|c|}{ Female $(n=298)$} & \multicolumn{2}{|c|}{ Male $(n=140)$} \\
\hline & $M$ & $S D$ & $M$ & $S D$ \\
\hline Age & 20.50 & 1.26 & 22.34 & 1.36 \\
\hline Spelling score & 54.91 & 3.11 & 54.39 & 3.44 \\
\hline Vocabulary score & 45.52 & 5.22 & 48.32 & 4.81 \\
\hline
\end{tabular}

Most (79.00\%) participants completed five sessions of word recognition; $20.32 \%$ completed ten sessions, and $0.68 \%$ completed 15 sessions

density competition (e.g., Luce \& Pisoni, 1998), item-level multiple regression analyses were performed for the zRT word estimates from each talker. As there were very high correlations between number of phonemes, number of syllables, and PLD20 ( $|r| \mathrm{s}$ between .82 and .92), principal components analysis (PCA) was used to reduce these to a single component, separately for the American and British English values; varimax rotation with Kaiser normalization was used. The component accounted for $92 \%$ of the variance, with higher values indicating greater phonological distinctiveness. Table 15 depicts the component loadings.

Words with estimates based on fewer than ten observations (indicating a low accuracy rate), were then dropped. Table 16 summarizes the regression results. Positive relationships were found between zRT and number of morphemes, token duration, and neighborhood density. Words with longer tokens, had more morphemes, or resided in dense neighborhoods (more confusable) were associated with slower latencies. Negative relationships were found between zRT and familiarity, prevalence, frequency, and the principal component. Words that were more familiar, prevalent, encountered more often, and more phonologically distinct (less confusable) were associated with faster RTs.

Linear mixed effects modeling We also analyzed the data using a linear mixed effects (LME) model for the same variables, using R (R Core Team, 2019). zRTs were fitted using the lme4 package (Bates, Maechler, Bolker, \& Walker, 2015);

Table 11 ALDT talker- and dialect-level behavioral estimates available for each item in the database

\begin{tabular}{ll}
\hline Measure & Description \\
\hline Accuracy & Response accuracy \\
Reaction time & Raw response latency \\
z-score reaction time & z-score response latency, by subject \\
& and by session \\
z-score (reaction time & z-score (response latency minus token \\
minus duration) & duration), by subject and by session \\
\hline
\end{tabular}

Talker-level estimates for intelligibility and confidence ratings from the WordID phases are also available as behavioral measures, as described in the previous section
Table 12 Accuracy and response latency correlations between talkers for words (upper triangle) and nonwords (lower triangle)

\begin{tabular}{lllllll}
\hline Talker & F1 & F2 & F3 & M1 & M2 & M3 \\
\hline Accuracy & & & & & & \\
F1 & & .75 & .76 & .76 & .75 & .73 \\
F2 & .54 & & .77 & .74 & .80 & .75 \\
F3 & .57 & .59 & & .76 & .78 & .80 \\
M1 & .57 & .54 & .56 & & .75 & .74 \\
M2 & .53 & .66 & .59 & .54 & & .77 \\
M3 & .58 & .53 & .62 & .60 & .56 & \\
$z R T$ & & & & & & \\
F1 & & .72 & .72 & .69 & .72 & .67 \\
F2 & .59 & & .76 & .72 & .74 & .68 \\
F3 & .62 & .67 & & .72 & .72 & .73 \\
M1 & .59 & .60 & .64 & & .68 & .64 \\
M2 & .59 & .61 & .60 & .58 & & .70 \\
M3 & .55 & .57 & .64 & .53 & .60 & \\
\hline
\end{tabular}

$p$ values for fixed effects were obtained using the lmerTest package (Kuznetsova, Brockhoff, \& Christensen, 2016). The influence of the variables was treated as fixed effects. Random intercepts for participants and items, and random slopes for frequency (lgSUBTLCD), NUSFAM, phonological neighborhood density, and PCA were included in the model.

As can be seen in Table 17, the pattern of results converges with those obtained in the item-level regression analyses. Inhibitory effects on zRT were observed for number of morphemes, token duration, and neighborhood density, while facilitatory effects on zRT were observed for familiarity, prevalence, frequency, and the principal component.

Taken together, these patterns replicate the more robust findings in auditory lexical decision, such as facilitation for more frequent words and competition between similar sounding words. They are also consistent with findings from visual lexical decision for word prevalence (Brysbaert et al., 2019), which has not been previously explored in the auditory domain.

Table 13 Accuracy and response latency correlations between dialects for words (upper triangle) and nonwords (lower triangle)

\begin{tabular}{llll}
\hline Dialect & Singapore & American & British \\
\hline Accuracy & & & \\
Singapore & & .84 & .84 \\
American & .64 & & .85 \\
British & .71 & .67 & \\
$z R T$ & & & .80 \\
Singapore & & .82 & .82 \\
American & .73 & & \\
British & .72 & .73 & \\
\hline
\end{tabular}


Table 14 Intelligibility standardized regression coefficients for item-level regression analysis across talkers

\begin{tabular}{|c|c|c|c|c|c|c|}
\hline Variable & $\mathrm{F} 1$ & $\mathrm{~F} 2$ & F3 & M1 & M2 & M3 \\
\hline NUSFAM & $.43 * * *$ & $.43 * * *$ & $.51 * * *$ & $.49 * * *$ & $.44 * * *$ & $.46^{* * * *}$ \\
\hline Prevalence & $.15 * * *$ & $.16 * * *$ & $.18 * * *$ & $.18 * * *$ & $.18 * * *$ & $.20 * * *$ \\
\hline $\begin{array}{l}\text { Phonological neighborhood density } \\
\text { (substitution, addition, and deletion) }\end{array}$ & $-.15^{* * *}$ & $-.12 * * *$ & $-.10^{* * *}$ & $-.13 * * *$ & $-.10 * * *$ & $-.10 * * *$ \\
\hline PLD20 & $.11 * * *$ & $.12 * * *$ & $.10 * * *$ & $.11 * * *$ & $.13 * * *$ & $.12 * * *$ \\
\hline lgSUBTLCD & $.06 * * *$ & $.05 * * *$ & $.05 * * *$ & $.03 * *$ & $.08 * * *$ & $.05 * * *$ \\
\hline Adjusted $R^{2}$ & $.33^{* * * *}$ & $.34 * * *$ & $.43 * * *$ & $.41 * * * *$ & $.37 * * *$ & $.40 * * *$ \\
\hline
\end{tabular}

$* * p<.01, * * * p<.001$

\section{Virtual factorial experiments}

We have already described some regression and lme analyses based on the megastudy approach in the earlier sections, for both word identification and auditory lexical decision. The database can also be used to do auditory lexical decision virtual experiments for smaller word lists, such as those found in factorial experiments. One important feature of the AELP multi-talker database is that different participants heard different tokens across the six talkers. Hence, we can essentially do a total of three to six virtual replications, depending on whether dialect-level or talker-level estimates are used. An obvious advantage of this is that multiple replications would provide more confidence on the robustness and generalizability of any observed effects.

In the following sections, we describe three such virtual experiments on a lexical property (word frequency), a structural property (phonological onset-density), and a semantic property (number of features) that have been reported in the literature.

Word frequency Taft and Hambly (1986) reported that high frequency words were responded to more accurately and faster than low frequency words in their Experiment 4. We performed a $2 \times 6$ mixed-design analysis of variance (ANOVA) using zRT as the dependent variable, with Frequency (high, low) as the between-items factor and Talker (F1 to M3) as the within-items factor, on 38 of their 48 words found in the AELP database. The frequency effect was replicated and depicted in Fig. 2. High-frequency words were associated

Table 15 Principal component loadings

\begin{tabular}{lll}
\hline Predictors & \multicolumn{2}{l}{ Loading } \\
\cline { 2 - 3 } & American English & British English \\
\hline Number of phonemes & .98 & .98 \\
Number of syllables & .95 & .96 \\
PLD20 & .95 & .95 \\
\hline
\end{tabular}

with more accurate, $F(1,36)=11.79, M S e=.04, p<.01$, and faster responses, $F(1,36)=14.42, M S e=.36, p<.01$, than low-frequency words.

Onset density Vitevitch (2002) reported that words with few neighbors sharing the initial phoneme (sparse onset density) were responded to more quickly than words with many neighbors sharing the initial phoneme (dense onset density) in his Experiment 2, with no differences in accuracy. We performed a $2 \times 6$ mixed-design ANOVA with Onset Density (sparse, dense) as the between-items factor and Talker as the withinitems factor, on 84 of his 90 words found in the AELP database. The onset density effect was replicated and depicted in Fig. 3. Sparse-onset words were associated with faster responses, $F(1,82)=7.47, \mathrm{MSe}=.65, p<.01$, than denseonset words, with no differences in accuracy, $F<1$.

Number of features Sajin and Connine (2014) reported that words with high number of features $(\mathrm{NoF})$ were responded to more quickly and accurately than words with low $\mathrm{NoF}$ in their Experiment 1 . We performed a $2 \times 6$ mixed-design ANOVA with NoF (low, high) as the between-items factor and Talker as the within-items factor, on all 115 words found in the AELP database. The NoF effect was replicated and depicted in Fig. 4. High NoF words were associated with more accurate, $F(1$, $113)=8.67, \mathrm{MSe}=.05, p<.01$, and faster responses, $F(1$, $113)=8.23, \mathrm{MSe}=.69, p<.01$, than low NoF words.

In the future, when additional word properties are invented or discovered, users could use the RT data in the database to conduct more of such virtual experiments in tandem with running actual factorial designs, in order to obtain converging evidence and replications for hypothesized effects.

\section{The AELP website}

Figure 5 shows the homepage of the database's website. It is separated into three main sections. The Generate section allows users to generate a list of words from the database with user-specified lexical properties and behavioral data. The 
Table 16 zRT standardized regression coefficients for item-level regression analyses across talkers

\begin{tabular}{|c|c|c|c|c|c|c|}
\hline Variable & F1 & $\mathrm{F} 2$ & F3 & M1 & M2 & M3 \\
\hline Number of morphemes & $.07 * * *$ & $.07 * * *$ & $.06 * * *$ & $.07 * * *$ & $.07 * * *$ & $.08 * * *$ \\
\hline NUSFAM & $-.23 * * *$ & $-.21 * * *$ & $-.16^{* * *}$ & $-.16^{* * *}$ & $-.20 * * *$ & $-.18 * * *$ \\
\hline Prevalence & $-.08 * * *$ & $-.11 * * *$ & $-.09 * * *$ & $-.08 * * *$ & $-.09 * * *$ & $-.07 * * *$ \\
\hline Phonological neighborhood density (substitution, addition, and deletion) & $.21 * * *$ & $.18 * * *$ & $.19 * * *$ & $.17 * * *$ & $.19 * * *$ & $.21 * * *$ \\
\hline lgSUBTLCD & $-.17 * * *$ & $-.13 * * *$ & $-.14 * * *$ & $-.11 * * *$ & $-.17 * * *$ & $-.14 * * *$ \\
\hline PCA & $-.14 * * *$ & $-.04 * * *$ & $-.07 * * *$ & $-.04 * *$ & -.01 & $-.07 * * *$ \\
\hline Duration & $.68 * * *$ & $.69 * * *$ & $.80 * * *$ & $.74 * * *$ & $.59 * * *$ & $.69 * * *$ \\
\hline Adjusted $R^{2}$ & $.55^{* * *}$ & $.62 * * *$ & $.68 * * *$ & $.62 * * *$ & $.53^{* * *}$ & $.57 * * *$ \\
\hline
\end{tabular}

$* * p<.01, * * * p<.001$

Submit section allows users to submit a list of words to obtain user-specified lexical properties and behavioral data from the database. Users can also download the relevant sound files from these two sections. The final Downloads section allows users to download all sound files, trial-level lexical decision data, and a few other useful lists.

\section{Generate}

Figure 6 illustrates part of the Generate section page with a user-specified example. Here, the user wants a list of five- and six-syllable words and nonwords for British English from the database, and to include IPA pronunciations for the latter. The user would check the relevant properties, and can use the slider to limit the range for the number of syllables property in the phonological metrics section. The user then clicks the download button at the bottom of the page and the relevant properties will be retrieved as a .csv file named aelp_data.csv, stored in a .zip file called aelp.zip. Figure 7 shows the csv file as opened in Microsoft Excel for the example described.

\section{Submit}

Figures 8 and 9 illustrate part of the Submit section page with a user-specified example. Here, the user inputs five words for
American English and wants to retrieve the phonological neighborhood density (substitutions, additions, and deletions), the identity of the neighbors, word frequency, the zRT data for talker F2, and her sound files for these words. The user checks the relevant boxes, clicks download and will obtain a zip file that contains the wav files stored in a Sound Files folder together with the requested data in a csv file. Figure 10 shows the csv file as opened in Microsoft Excel for the example described.

For the words abacus and zucchini, there are no phonological neighbors, which is reflected in the NULL response for the iden_phono_n_sad field. Besides the mean zRT values (f2_ldt_zrt_m) for talker F2 requested by the user, the database will also automatically provide the $S D$ s (f2_ldt_zrt_sd) and number of observations (f2_ldt_zrt_n) that the mean value is derived from. The database will automatically provide $S D$ s and $n \mathrm{~s}$, where available, for all properties when the associated means are requested.

\section{Downloads}

In this section, users can download all sound files for words and nonwords, and all trial-level auditory lexical decision data for the six talkers. Figure 11 shows the trial-level data structure. A text file variables.txt describing the various fields is included in the zip file.

Table 17 zRT linear mixed model estimates for fixed and random effects across talkers

\begin{tabular}{lllllllll}
\hline Fixed effects & $\mathrm{F} 1$ & $\mathrm{~F} 2$ & $\mathrm{~F} 3$ & $\mathrm{M} 1$ & $\mathrm{M} 2$ & $\mathrm{M} 3$ \\
\hline Intercept & -0.05 & $-0.38^{* * *}$ & $-0.50^{* * *}$ & $-0.68^{* * *}$ & 0.01 & $-0.29 * * *$ \\
Duration & $0.002^{* * *}$ & $0.002^{* * *}$ & $0.002^{* * *}$ & $0.002^{* * *}$ & $0.002^{* * * *}$ & $0.002^{* * *}$ \\
PCA & $-0.06^{* * *}$ & $-0.02^{*}$ & $-0.04^{* *}$ & $-0.05^{* * *}$ & -0.01 & $-0.04^{* * *}$ \\
Number of morphemes & $0.04 * * *$ & $0.05^{* * *}$ & $0.05^{* * *}$ & $0.05^{* * *}$ & $0.05^{* * *}$ & $0.06^{* * *}$ \\
Phonological neighborhood density (substitution, addition, and deletion) & $0.01^{* * *}$ & $0.01^{* * *}$ & $0.01^{* * *}$ & $0.01^{* * *}$ & $0.01^{* * *}$ & $0.01^{* * *}$ \\
LgSUBTLCD & $-0.08^{* * *}$ & $-0.07^{* * *}$ & $-0.08^{* * *}$ & $-0.06^{* * *}$ & $-0.1 * * *$ & $-0.08^{* * *}$ \\
Prevalence & $-0.12^{* * *}$ & $-0.15^{* * *}$ & $-0.15^{* * *}$ & $-0.15^{* * *}$ & $-0.15^{* * *}$ & $-0.12^{* * *}$ \\
NUSFAM & $-0.19^{* * *}$ & $-0.17^{* * *}$ & $-0.16^{* * *}$ & $-0.17^{* * *}$ & $-0.17^{* * *}$ & $-0.17^{* * *}$ \\
\hline
\end{tabular}

$* p<.05, * * p<.01, * * * p<.001$ 


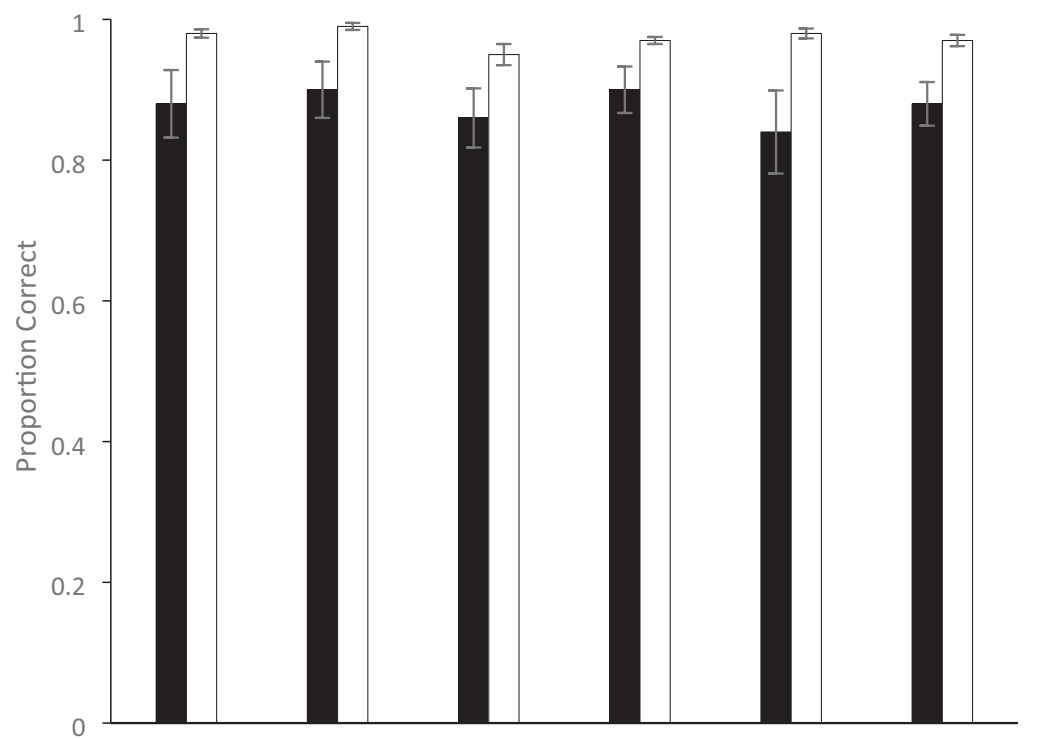

- Low Frequency

$\square$ High Frequency

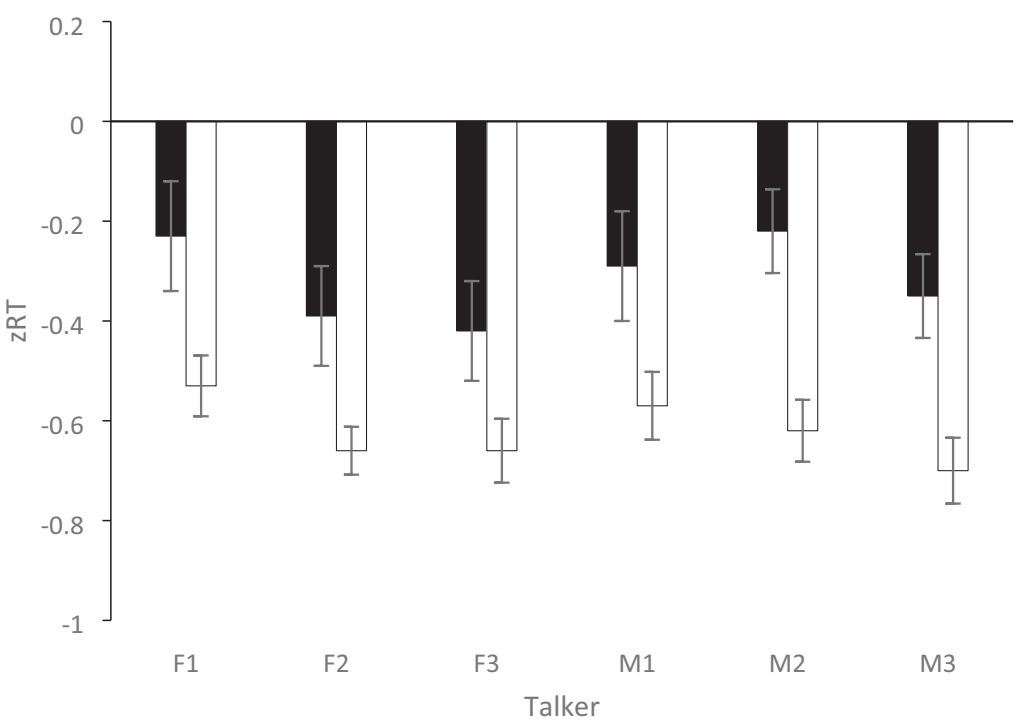

Fig. 2 Accuracy (top panel) and latency (bottom panel) for virtual experiment of Taft and Hambly (1986) Experiment 4 


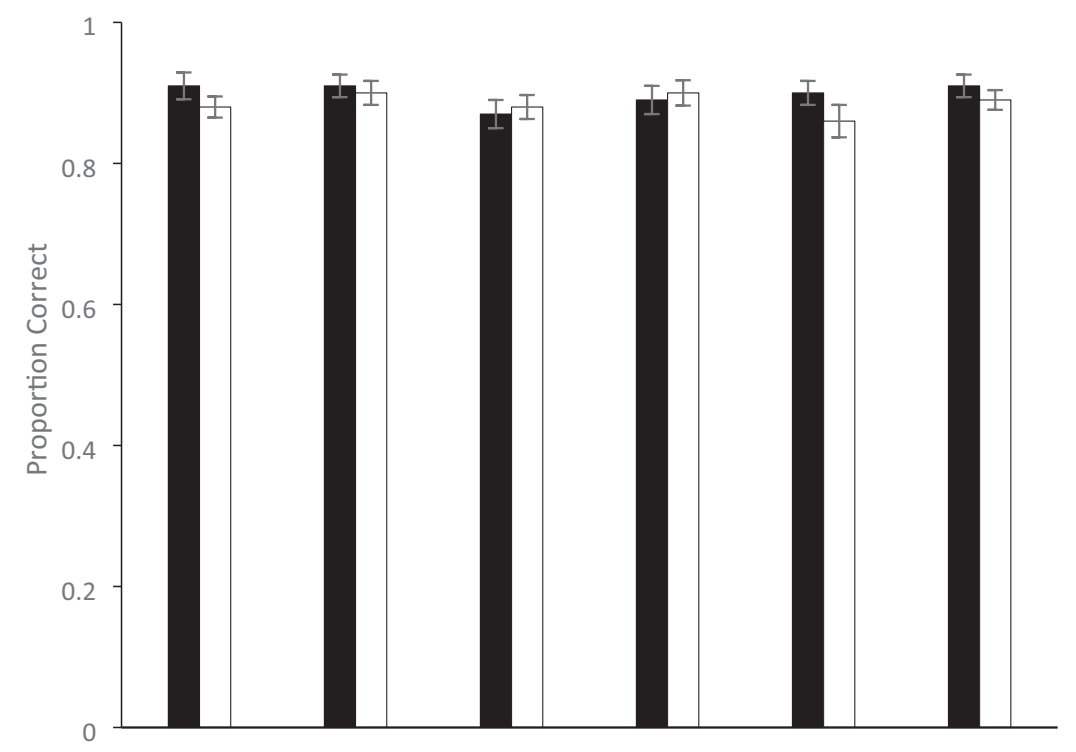

- Sparse Onset

$\square$ Dense Onset

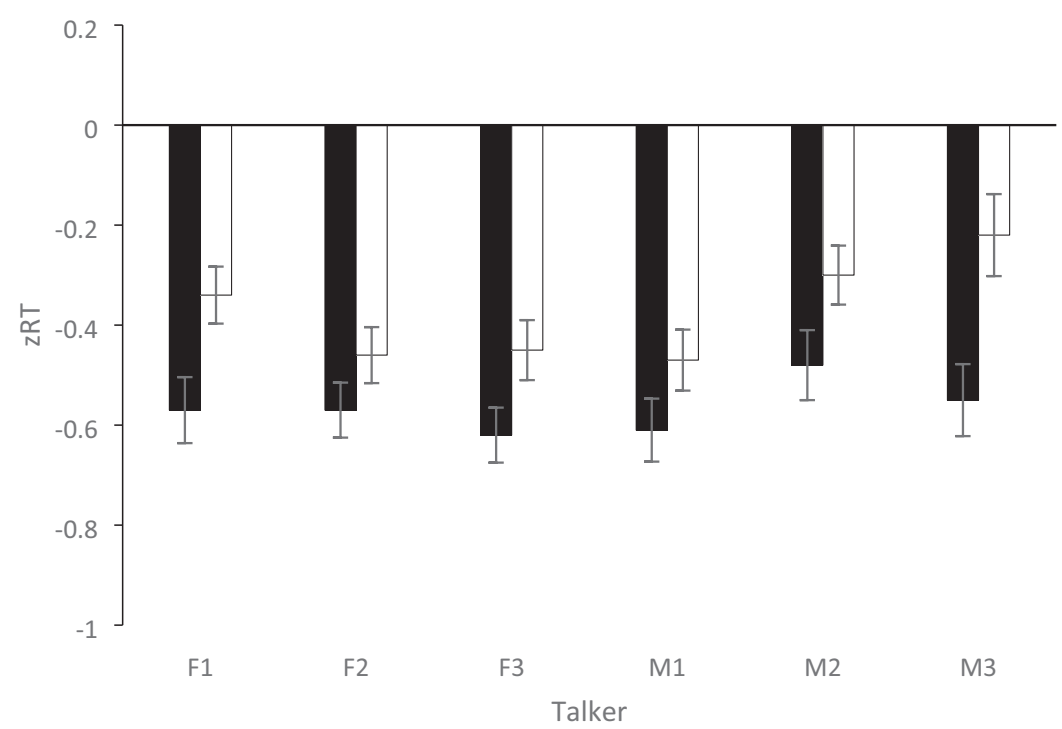

Fig. 3 Accuracy (top panel) and latency (bottom panel) for virtual experiment of Vitevitch (2002) Experiment 2 


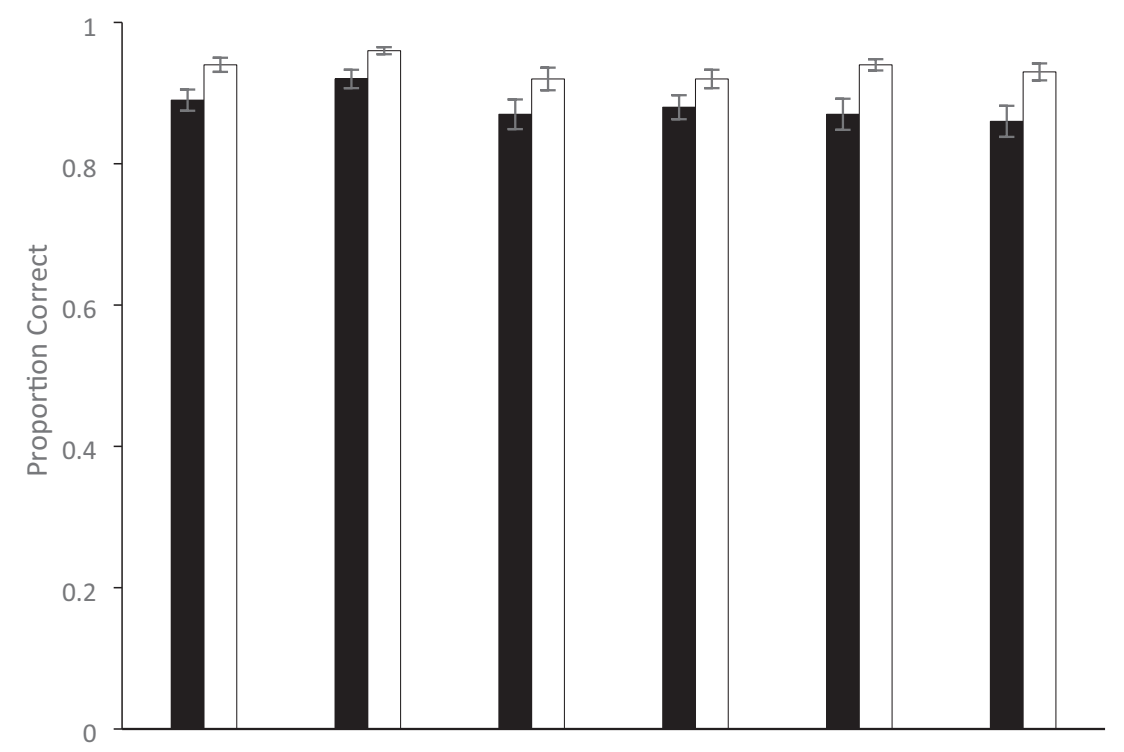

- Low NoF

$\square$ High NoF

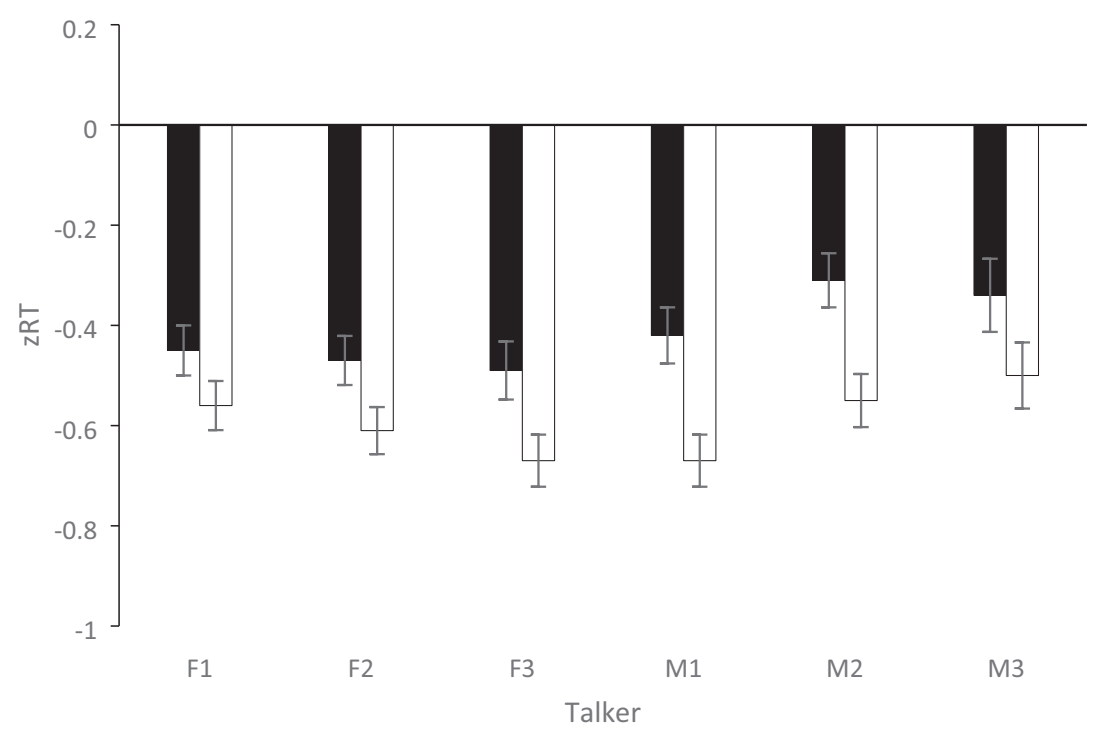

Fig. 4 Accuracy (top panel) and latency (bottom panel) for virtual experiment of Sajin and Connine (2014) Experiment 1

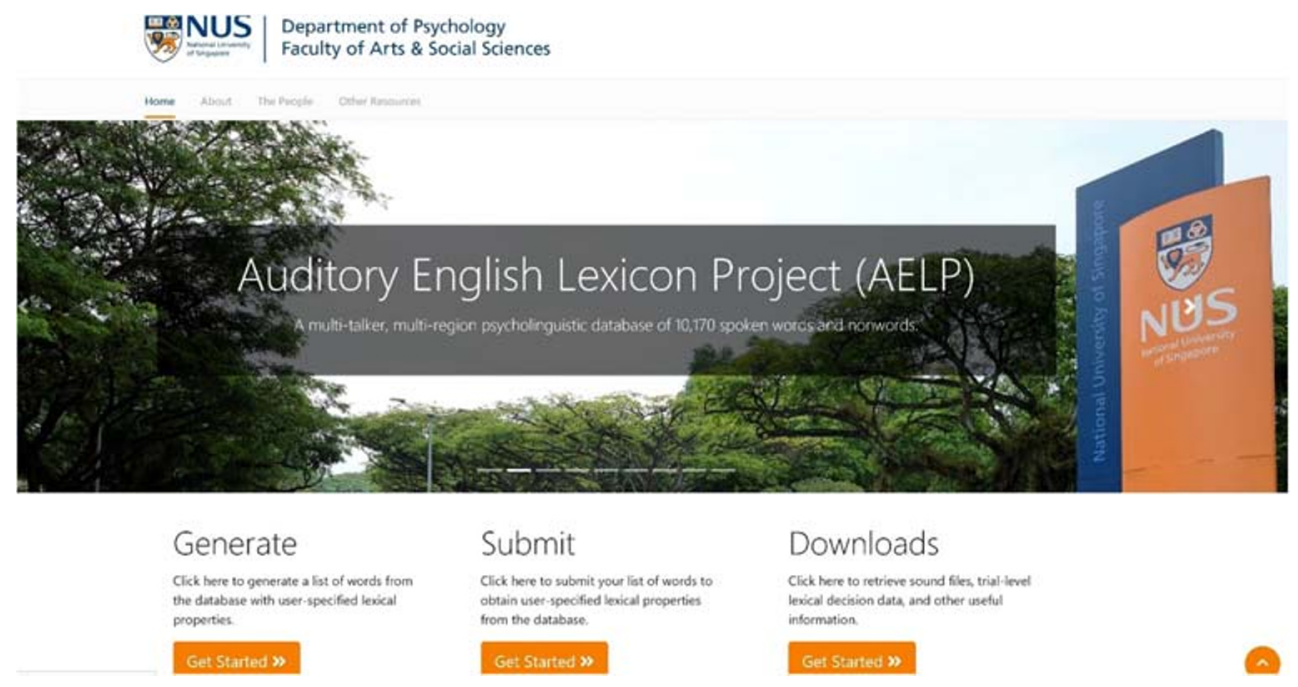

Fig. 5 Home page of the AELP website 


\section{Generate}

Select the data type and dialect, then specify the metrics and variables required, along with the range of values. You can also specify whether you want the behavioural data and sound files.

\section{Select Data:}

Words only Words and Nonwords

$\square$ Include IPA pronunciations (nonwords only)

\section{Select Metrics:}

Select Dialect:

$\bigcirc$ American (US) • British (UK)

\section{Orthographic}

$\square$ Word Length $\mathbf{0}$

$\square$ Neighbourhood Density $\mathbf{0}$

Substitutions only $\mathbf{0}$

(10) Substitutions, additions and deletions 1

$\operatorname{Min} 2$

Min 0

Min 0

$\square$ Neighbourhood Frequency $\mathbf{0}$

(1) Substitutions only $\mathbf{O}$

- 1 Substitutions, additions and deletions (1)

$\square$ Identity of Neighbours $\mathbf{0}$

Substitutions only $\mathbf{0}$

(11) Substitutions, additions and deletions

$\square$ Orthographic Spread $\mathbf{0}$

$\square$ Orthographic Uniqueness Point $\mathbf{0}$

$\square$ Orthographic Levenshtein Distance-20 (OLD-20) $\mathbf{0}$

$\square$ Orthographic C Coefficient (3)

$\square$ Summed Bigram Frequency $\mathbf{0}$

Phonological

$\square$ Number of Phonemes

Number of Syllables

$\square$ Neighbourhood Density $\mathbf{0}$

Substitutions only $\mathbf{O}$

(1) Substitutions, additions and deletions (1)

Use me to avoid scrolling to the bottom!

Substitutions, adations, and deletions $\mathbf{0}$

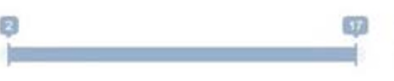

$17 \quad \operatorname{Max}$

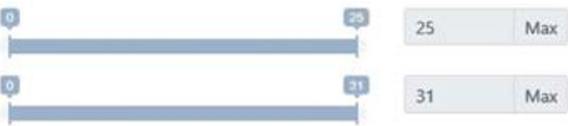

Min 0.1505

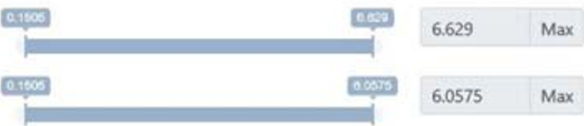

Min 0.1505

0.1895

Min 0

Min 2

Min 1

Min 0

Min 0.000

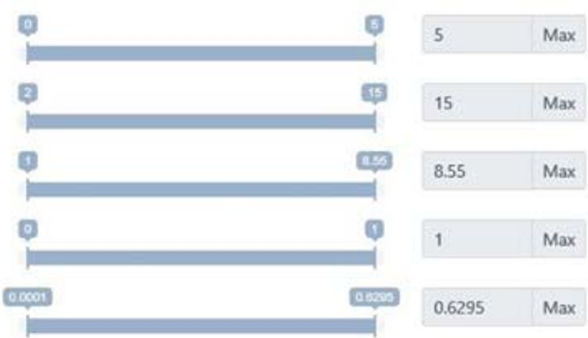

Fig. 6 Generating a list of items based on user-specified properties
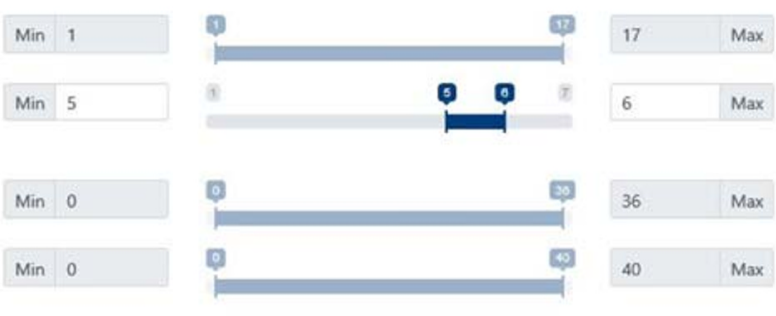

Min 0.1505
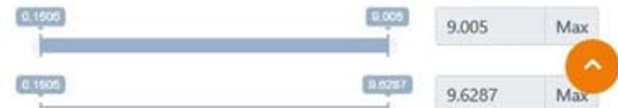

Min 0.1505

9.6287 


\begin{tabular}{|c|c|c|c|c|c|}
\hline 2 & A & B & C & D & $\mathrm{E}$ \\
\hline 1 & word_uk & n_syll & nonword & nonword_ipa & n_syll_nw \\
\hline 2 & abbreviation & 5 & abbreriotion & əbri:rI'əひf(ə)n & 5 \\
\hline 3 & abnormality & & abnorcaloty & abnn'kaləuti & 5 \\
\hline 4 & abolitionist & & abofitialist & əbo'frtiəlist & 5 \\
\hline 5 & abominable & & abomogable & ə'boməgab(ə)| & 5 \\
\hline 6 & accommodation & & accomrogation & əkpmrəv'gerf(ə)n & 5 \\
\hline 7 & accompaniment & 5 & accombarimics & ə'k^mb(ə)rImIks & 5 \\
\hline 8 & actuality & 5 & actuority & akt jju' priti & 5 \\
\hline 9 & administrative & & adminustrotion & ad'minustrəufən & 5 \\
\hline 10 & administrator & & adminustrotar & ad'minustrəuta: & 5 \\
\hline 11 & agricultural & & agrilipteral & agri' Inptərəl & 5 \\
\hline 12 & alliteration & & allitenative & əlitə'nertrv & 5 \\
\hline 13 & amateurism & 5 & amacourism & 'amakəuriz(ə)m & 5 \\
\hline 14 & Americanise & 5 & amerilanize & ə'merIl(ə)n^Iz & 5 \\
\hline 15 & amphitheatre & & amphitreaten & 'amfrtri:ertan & 5 \\
\hline 16 & amplification & & amplirization & amplirıI'zeIf(ə)n & 5 \\
\hline 17 & anniversary & & annisermagy & anr'sə:məgi & 5 \\
\hline 18 & anonymously & 5 & anonygously & ə'nnnIgəsli & 5 \\
\hline 19 & anthropology & 5 & anthrocalomy & , anӨrəu'kaləumi & 5 \\
\hline 20 & antibiotic & & antifiuter & ,antıfru:'tə & 5 \\
\hline 21 & anticipated & 5 & anticimated & an'tisimeitid & 5 \\
\hline 22 & antipersonnel & & anticermennic & antIsə:me'nIk & 5 \\
\hline 23 & apologetic & & apolumetic & әpplण'metrk & 5 \\
\hline 24 & appendicitis & 5 & appenmiciton & ә.penmi'sitən & 5 \\
\hline 25 & appropriation & 5 & approchiation & ә, prout $\int I^{\prime}$ eI $\int(\partial) n$ & 5 \\
\hline 26 & archaeology & & archaealomy & a:ki:'vləmi & 5 \\
\hline 27 & architectural & 5 & architullerly & a:kI'tu:lə:li & 5 \\
\hline 28 & argumentation & 5 & argucenraters & ,a:gjusøn' restəs & 5 \\
\hline 29 & argumentative & 5 & argucengators & a:gju'sengətग:z & 5 \\
\hline 30 & aristocratic & 5 & aristustatic & ,aristo'statik & 5 \\
\hline 31 & arithmetical & 5 & arithramical & , $\operatorname{arr} \theta$ 'ramik(ə)I & 5 \\
\hline 32 & arithmetician & & arithtenician & ə, rI $\theta$ tə'nI $(\partial) n$ & 5 \\
\hline 33 & articulation & 5 & articonation & a:,trkəひ'nertiən & 5 \\
\hline$\because$ & aelp_data & $\oplus^{-}$ & & & \\
\hline
\end{tabular}

Fig. 7 List of words, the yoked nonwords (and IPA transcriptions), and number of syllables 


\section{Submit}

Select input method, then specify the metrics and variables required. Data will be returned only for words found in the database. You can also specify whether you want the behavioural data and sound files.

Method of Submission:

- Input List of Words

abacus

abide

delight

zoom

zucchini

Note: Words should be seperated by line-breaks or spaces, Maximum number of entires is

1000 words.

\section{Select Data:}

- Words only $O$ Words and Nonwords

Include IPA pronunciations (nonwords only)

\section{Select Metrics:}

Select Dialect:

- American (US) O British (UK)

\section{Orthographic}

$\square$ Word Length 1

$\square$ Neighbourhood Density 9

Substitutions only $\mathbf{C}$

Substitutions, additions and deletions $\mathbf{0}$

$\square$ Neighbourhood Frequency $\mathbf{0}$

-1] Substitutions only $\mathbf{O}$

Substitutions, additions and deletions $\mathbf{0}$

$\square$ Identity of Neighbours $\mathbf{0}$

Lubstitutions only $\mathbf{C}$

Substitutions, additions and deletions 0

$\square$ Orthographic Spread

$\square$ Orthographic Uniqueness Point 0

$\square$ Orthographic Levenshtein Distance-20 (OLD-20)

$\square$ Orthographic C Coefficient 1

$\square$ Summed Bigram Frequency (

Phonological

$\square$ Number of Phonemes

$\square$ Number of Syllables

$\square$ Neighbourhood Density $\mathbf{0}$

$\square$ Substitutions only $\mathbf{0}$

$\square$ Substitutions, additions and deletions $\mathbf{0}$

$\square$ Neighbourhood Frequency $\mathbf{C}$

Substitutions only $\mathbf{0}$

Substitutions, additions, and deletions 1

च Identity of Neighbours (1)

$\square$ Substitutions only $\mathbf{C}$

Substitutions, additions and deletions $\mathbf{0}$

$\square$ Phonological Spread $\mathbf{0}$

$\square$ Phonological Uniqueness Point $\mathbf{\theta}$

$\square$ Phonological Levenshtein Distance-20 (PLD-20)

$\square$ Phonological C Coefficient $\mathbf{0}$

$\square$ Summed Biphone Frequency $\mathbf{a}$

Fig. 8 Submitting a list of items based on user specified properties (data and metrics) 


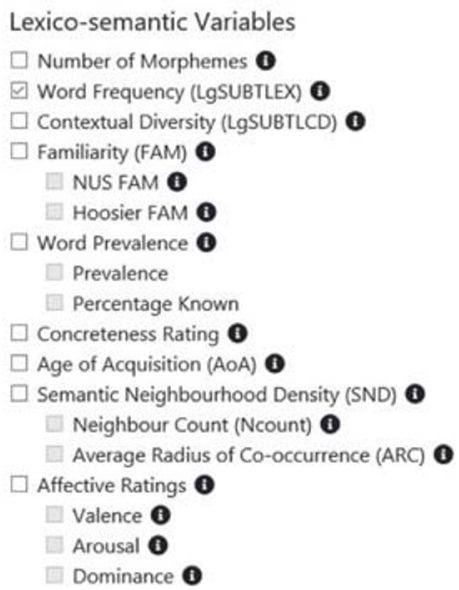

\section{Select Behavioural Data:}

Talker-level Estimates

For these talkers:

$\square$ Singaporean, Female (F1)

$\square$ singaporean, Male (M1)

$\square$ Intelligibility Rate (ID) $\mathbf{0}$

$\square$ Confidence Rating 1

$\square$ LDT Accuracy $\mathbf{0}$

$\square$ LDT Reaction Time (RT) $\mathbf{0}$

$\square$ LDT z-score Reaction Time (zRT) 0

$\square$ LDT z-score Reaction Time minus Duration (zRTmDur)

Dialect-level Estimates

For these dialects:

$\square$ Singapore English (SG)

IDT Accuracy $\mathbf{0}$

L LDT Reaction Time (RT) $\mathbf{0}$

- LDT z-score Reaction Time (zRT) $\mathbf{0}$

[D LDT z-score Reaction Time minus Duration (zRTmDur) $\mathbf{C}$

\section{Select Sound File Duration:}

Talker-level Estimates

$\square$ Singaporean, Female (F1)

$\square$ Singaporean, Male (M1)

$\square$ American, Female (F2)

$\square$ American, Male (M2)

$\square$ American English (US)

$\square$ Singapore English (SG)

\section{Select Sound Files:}

$$
\begin{aligned}
& \square \text { I do not need sound files } \\
& \square \text { Singaporean, Female (F1) } \\
& \square \text { Singaporean, Male (M1) }
\end{aligned}
$$

$\square$ British, Female (F3)

$\square$ British, Male (M3)

$\square$ British English (UK)

Fig. 9 Submitting a list of items based on user specified properties (lexico-semantic variables, behavioral data, and sound files)

Also available for download are lists of homophones (in csv and Excel format) for American and British
English, together with the frequency of each homophone response in the WordID data, and lists of participant 


\begin{tabular}{|c|c|c|c|c|c|c|c|}
\hline$\Delta$ & A & B & C & D & E & $\mathrm{F}$ & G \\
\hline 1 & word_us & phono_n_dens_sad i & iden_phono_n_sad & Igsubltwf & f2_ldt_zrt_m & f2_Idt_zrt_sd & f2_Idt_zrt_n \\
\hline 2 & abacus & 0 & NULL & 1.113943352 & -0.206877534 & 0.826083967 & 26 \\
\hline 3 & abide & 4 & [abed; abode; aside; bide] & 2.1430148 & -0.824567702 & 0.458120159 & 32 \\
\hline 4 & delight & 4 & [alight; daylight; delete; polite] & 2.460897843 & -1.061079439 & 0.439419765 & 32 \\
\hline 5 & zoom & 81 & [boom; doom; loom; room; tomb; whom; womb; zoo] & 2.260071388 & -0.122038661 & 0.667218755 & 26 \\
\hline 6 & zucchini & 0 & NULL & 1.698970004 & -0.48123793 & 0.519724227 & 24 \\
\hline
\end{tabular}

Fig. 10 Properties requested in the submit example

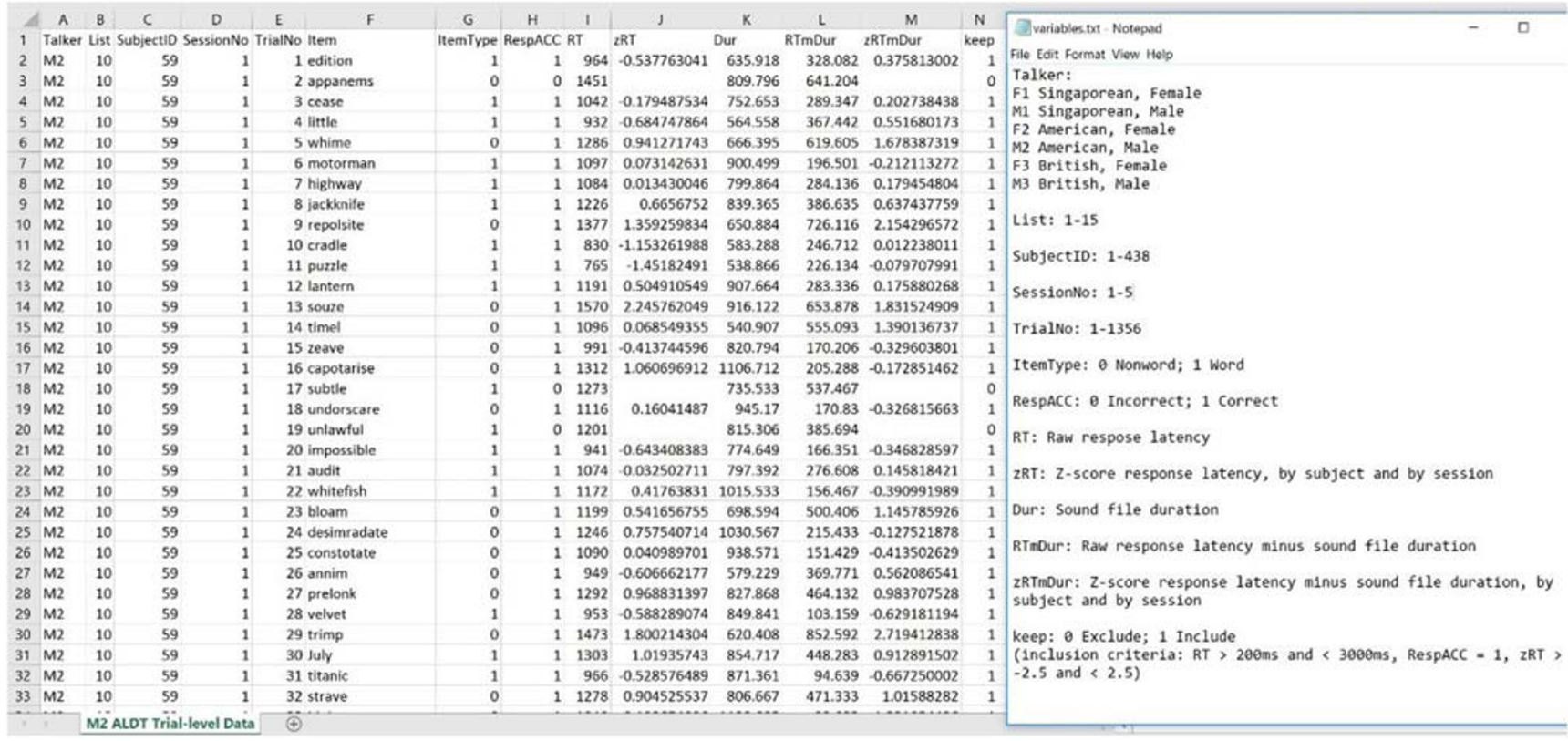

Fig. 11 Trial-level auditory lexical decision task data structure

characteristics for the ALD megastudy; these are described in Appendix 4. There is also a list of American and British spelling equivalents (e.g. authorizationauthorisation, color-colour) so that users can input the correct spelling depending on which dialect they choose on the website.

\section{Conclusions}

The AELP is the largest multi-talker database of spoken words and nonwords to date, and will complement other singletalker large databases such as BALDEY, MEGALEX, and MALD. It is the first multi-region spoken word database that we are aware of, with speakers from three dialects of English. It is also the first to provide intelligibility norms for all tokens, which will be useful for researchers to decide whether the tokens can be used based on their requirements. The behavioral data replicates the classic findings of word frequency facilitation and word-form similarity inhibition for auditory lexical decision, and also for word identification, which has not been shown before. It has further demonstrated facilitation effects for newer variables such as prevalence that has not been tested in the spoken domain. We hope that researchers will find the database useful.

Open Practices Statement The data and materials are available at https://inetapps.nus.edu.sg/aelp/ (https://doi.org/10.25542/ $5 \mathrm{cvf}-\mathrm{vv} 50)$. None of the data reported here were preregistered in an independent, institutional registry.

Supplemental Material There are three supplemental documents appended to this paper. S1 is the annotated Python script that was used to retrieve the phonological transcriptions from Oxford Dictionaries using their API; this is correct as of December 2019. S2 is an Excel file containing the base dataset of 26,604 words used for computing the structural properties of the AELP words. S3 contains the correlation matrices of all structural, lexico-semantic variables, and behavioural data for words and nonwords in an Excel file. 


\section{Appendix 1 Familiarity rating scale}

\begin{tabular}{ll}
\hline Score & Label \\
1 & I have never seen the word before. \\
2 & I think that I might have seen the word somewhere before. \\
3 & I am somewhat sure that I have seen the word before, but am not certain. \\
4 & I have definitely seen the word before, but I don't know its meaning. \\
5 & I am certain that I have seen the word before, but only have a vague idea about its meaning. \\
6 & I think I might know the meaning of the word, but am not certain that the meaning I know is correct. \\
7 & I recognize the word and am confident that I know at least one meaning. \\
\hline
\end{tabular}

\section{Appendix 2 Descriptive statistics of database properties}

Table 18 Structural properties

\begin{tabular}{|c|c|c|c|c|c|c|c|c|c|c|c|}
\hline \multirow[t]{2}{*}{ Property } & \multirow[t]{2}{*}{ Database field } & \multicolumn{5}{|c|}{ American English } & \multicolumn{5}{|c|}{ British English } \\
\hline & & $N$ & Min & $\operatorname{Max}$ & $M$ & $S D$ & $N$ & Min & $\operatorname{Max}$ & $M$ & $S D$ \\
\hline \multicolumn{12}{|l|}{ Words } \\
\hline \multicolumn{12}{|l|}{ Orthographic } \\
\hline Word length & word_length & 10170 & 2 & 17 & 7.20 & 2.44 & 10170 & 2 & 17 & 7.21 & 2.44 \\
\hline \multicolumn{12}{|l|}{ Neighborhood density } \\
\hline Substitutions only & ortho_n_dens_s & 10170 & 0 & 25 & 1.82 & 3.55 & 10170 & 0 & 25 & 1.82 & 3.53 \\
\hline Substitutions, additions, and deletions & ortho_n_dens_sad & 10170 & 0 & 31 & 2.47 & 4.45 & 10170 & 0 & 31 & 2.46 & 4.43 \\
\hline \multicolumn{12}{|l|}{ Neighborhood frequency } \\
\hline Substitutions only & ortho_n_freq_s_m & 4204 & 0.15 & 5.83 & 2.21 & 0.74 & 4261 & 0.45 & 6.63 & 2.84 & 0.78 \\
\hline Substitutions, additions, and deletions & ortho_n_freq_sad_m & 5110 & 0.15 & 5.47 & 2.19 & 0.74 & 5178 & 0.45 & 6.06 & 2.81 & 0.78 \\
\hline \multicolumn{12}{|l|}{ Identity of neighbors } \\
\hline Substitutions only & iden_ortho_n_s & \multicolumn{10}{|c|}{ List of neighbors based on single letter substitution } \\
\hline Substitutions, additions, and deletions & iden_ortho_n_sad & \multicolumn{10}{|c|}{$\begin{array}{l}\text { List of neighbors based on single letter substitution, } \\
\text { addition, and deletion }\end{array}$} \\
\hline Orthographic spread & ortho_spread & 10170 & 0 & 5 & 0.80 & 1.14 & 10170 & 0 & 5 & 0.80 & 1.14 \\
\hline Orthographic uniqueness point & ortho_upoint & 10170 & 2 & 15 & 6.60 & 2.04 & 10170 & 2 & 15 & 6.61 & 2.04 \\
\hline Orthographic Levenshtein distance (OLD-20) & old20_m & 10170 & 1.00 & 8.55 & 2.71 & 1.01 & 10170 & 1.00 & 8.55 & 2.71 & 1.01 \\
\hline Orthographic $\mathrm{C}$ coefficient & ortho_c_coeff & 3359 & 0 & 1 & .30 & .28 & 3377 & 0 & 1 & .31 & .29 \\
\hline Summed bigram frequency & sum_bigram & 10170 & .00 & .63 & .07 & .06 & 10170 & .00 & .60 & .07 & .06 \\
\hline \multicolumn{12}{|l|}{ Phonological } \\
\hline Number of phonemes & n_phon & 10170 & 1 & 17 & 6.42 & 2.45 & 10170 & 1 & 17 & 6.17 & 2.40 \\
\hline Number of syllables & n_syll & 10170 & 1 & 7 & 2.41 & 1.16 & 10170 & 1 & 7 & 2.39 & 1.12 \\
\hline \multicolumn{12}{|l|}{ Neighborhood density } \\
\hline Substitutions only & phono_n_dens_s & 10170 & 0 & 35 & 3.24 & 5.74 & 10170 & 0 & 36 & 3.45 & 6.18 \\
\hline Substitutions, additions, and deletions & phono_n_dens_sad & 10170 & 0 & 39 & 4.15 & 6.87 & 10170 & 0 & 40 & 4.39 & 7.36 \\
\hline \multicolumn{12}{|l|}{ Neighborhood frequency } \\
\hline Substitutions only & phono_n_freq_s_m & 5043 & 0.15 & 7.83 & 2.29 & 0.82 & 5043 & 0.48 & 9.01 & 2.96 & 0.91 \\
\hline Substitutions, additions, and deletions & phono_n_freq_sad_m & 5819 & 0.15 & 6.94 & 2.27 & 0.80 & 5910 & 0.24 & 9.63 & 2.94 & 0.89 \\
\hline \multicolumn{12}{|l|}{ Identity of neighbors } \\
\hline Substitutions only & iden_phono_n_s & \multicolumn{10}{|c|}{ List of neighbors based on single phoneme substitution } \\
\hline Substitutions, additions, and deletions & iden_phono_n_sad & \multicolumn{10}{|c|}{$\begin{array}{l}\text { List of neighbors based on single phoneme substitution, } \\
\text { addition, and deletion }\end{array}$} \\
\hline Phonological spread & phono_spread & 10170 & 0 & 6 & 1.04 & 1.24 & 10170 & 0 & 5 & 1.04 & 1.24 \\
\hline Phonological uniqueness point & phono_upoint & 10170 & 2 & 15 & 5.78 & 1.85 & 10170 & 2 & 14 & 5.61 & 1.85 \\
\hline
\end{tabular}


Table 18 (continued)

\begin{tabular}{|c|c|c|c|c|c|c|c|c|c|c|c|}
\hline \multirow[t]{2}{*}{ Property } & \multirow[t]{2}{*}{ Database field } & \multicolumn{5}{|c|}{ American English } & \multicolumn{5}{|c|}{ British English } \\
\hline & & $N$ & Min & $\operatorname{Max}$ & $M$ & $S D$ & $N$ & Min & $\operatorname{Max}$ & $M$ & $S D$ \\
\hline Phonological Levenshtein distance (PLD-20) & pld20_m & 10170 & 1.00 & 7.80 & 2.47 & 1.00 & 10170 & 1.00 & 8.00 & 2.47 & 1.01 \\
\hline Phonological C coefficient & phono_c_coeff & 4300 & .00 & 1.00 & .30 & .25 & 4284 & .00 & 1.00 & .29 & .24 \\
\hline Summed biphone frequency & sum_biphone & 10167 & .00 & .67 & .06 & .06 & 10165 & .00 & .64 & .05 & .05 \\
\hline \multicolumn{12}{|l|}{ Phonographic } \\
\hline \multicolumn{12}{|l|}{ Neighborhood density } \\
\hline Substitutions only & pgraph_n_dens_s & 10170 & 0 & 19 & 1.19 & 2.70 & 10170 & 0 & 19 & 1.22 & 2.73 \\
\hline Substitutions, additions, and deletions & pgraph_n_dens_sad & 10170 & 0 & 24 & 1.69 & 3.45 & 10170 & 0 & 24 & 1.73 & 3.50 \\
\hline \multicolumn{12}{|l|}{ Neighborhood frequency } \\
\hline Substitutions only & pgraph_n_freq_s_m & 3154 & 0.30 & 5.52 & 2.29 & 0.76 & 3215 & 0.48 & 6.63 & 2.92 & 0.77 \\
\hline Substitutions, additions, and deletions & pgraph_n_freq_sad_m & 3973 & 0.15 & 5.52 & 2.26 & 0.75 & 4068 & 0.24 & 5.87 & 2.89 & 0.77 \\
\hline \multicolumn{12}{|l|}{ Identity of neighbors } \\
\hline Substitutions only & iden_pgraph_n_s & \multicolumn{10}{|c|}{$\begin{array}{l}\text { List of neighbors based on single letter and single } \\
\text { phoneme substitution }\end{array}$} \\
\hline Substitutions, additions, and deletions & iden_pgraph_n_sad & \multicolumn{10}{|c|}{$\begin{array}{l}\text { List of neighbors based on single letter and single } \\
\text { phoneme substitution, addition, and deletion }\end{array}$} \\
\hline Phonographic $\mathrm{C}$ coefficient & pgraph_c_coeff & 2553 & .00 & 1.00 & .34 & .31 & 2626 & .00 & 1.00 & .32 & .30 \\
\hline \multicolumn{12}{|l|}{ Nonwords } \\
\hline \multicolumn{12}{|l|}{ Phonological } \\
\hline IPA transcription & nonword_ipa & & & & & & & & & & \\
\hline Number of phonemes & n_phon_nw & 10170 & 2 & 17 & 6.51 & 2.43 & 10170 & 2 & 17 & 6.24 & 2.37 \\
\hline Number of syllables & n_syll_nw & 10170 & 1 & 8 & 2.45 & 1.18 & 10170 & 1 & 7 & 2.41 & 1.13 \\
\hline \multicolumn{12}{|l|}{ Neighborhood density } \\
\hline Substitutions only & phono_n_dens_s_nw & 10170 & 0 & 31 & 1.92 & 4.04 & 10170 & 0 & 31 & 2.12 & 4.34 \\
\hline Substitutions, additions, and deletions & phono_n_dens_sad_nw & 10170 & 0 & 39 & 2.27 & 4.66 & 10170 & 0 & 38 & 2.47 & 4.91 \\
\hline \multicolumn{12}{|l|}{ Neighborhood frequency } \\
\hline Substitutions only & phono_n_freq_s_m_nw & 3543 & 0.30 & 8.53 & 2.34 & 0.75 & 3735 & 0.48 & 7.20 & 3.00 & 0.81 \\
\hline Substitutions, additions, and deletions & $\underset{\text { nwo }}{\text { phono_freq_sad_m }}$ & 3802 & 0.30 & 8.53 & 2.39 & 0.76 & 3991 & 0.48 & 8.29 & 3.05 & 0.81 \\
\hline \multicolumn{12}{|l|}{ Identity of neighbors } \\
\hline Substitutions only & iden_phono_n_s_nw & \multicolumn{10}{|c|}{ List of word neighbors based on single phoneme substitution } \\
\hline Substitutions, additions, and deletions & iden_phono_n_sad_nw & \multicolumn{10}{|c|}{$\begin{array}{l}\text { List of word neighbors based on single phoneme substitution, } \\
\text { addition, and deletion }\end{array}$} \\
\hline Phonological spread & phono_spread_nw & 10170 & 0 & 5 & 0.68 & 1.07 & 10170 & 0 & 5 & 0.72 & 1.08 \\
\hline Phonological uniqueness point & phono_upoint_nw & 10170 & 2 & 11 & 4.27 & 1.06 & 10170 & 1 & 11 & 4.22 & 1.09 \\
\hline Phonological Levenshtein distance (PLD-20) & pld20_m_nw & 10170 & 1.00 & 9.90 & 2.99 & 1.33 & 10170 & 1.00 & 9.65 & 2.88 & 1.25 \\
\hline Phonological $\mathrm{C}$ coefficient & phono_c_coeff_nw & 2859 & .00 & 1.00 & .41 & .29 & 3016 & .00 & 1.00 & .41 & .28 \\
\hline Summed biphone frequency & sum_biphone_nw & 10170 & .00 & .40 & .04 & .05 & 10170 & .00 & .43 & .03 & .04 \\
\hline
\end{tabular}


Table 19 Lexico-semantic properties

\begin{tabular}{|c|c|c|c|c|c|c|}
\hline Property & Database field & $N$ & Min & Max & $M$ & $S D$ \\
\hline Number of morphemes & n_morph & 10170 & 1 & 5 & 1.51 & 0.66 \\
\hline $\begin{array}{l}\text { Part of speech (POS): adjective, determiner, noun, } \\
\text { pronoun, adverb, interjection, number, verb, } \\
\text { conjunction, name, preposition }\end{array}$ & pos & & & & & \\
\hline Word frequency & lgsubtlwf & $\begin{array}{l}9949 \\
9968\end{array}$ & $\begin{array}{l}0.30 \\
0.48\end{array}$ & $\begin{array}{l}5.47 \\
5.87\end{array}$ & $\begin{array}{l}2.16 \\
2.80\end{array}$ & $\begin{array}{l}0.87 \\
0.93\end{array}$ \\
\hline Contextual diversity & lgsubtlcd & $\begin{array}{l}9949 \\
9968\end{array}$ & $\begin{array}{l}0.30 \\
0.48\end{array}$ & $\begin{array}{l}3.92 \\
4.64\end{array}$ & $\begin{array}{l}2.01 \\
2.62\end{array}$ & $\begin{array}{l}0.79 \\
0.85\end{array}$ \\
\hline \multicolumn{7}{|l|}{ Familiarity (FAM) } \\
\hline NUS FAM & nusfam_m & 10170 & 2.17 & 7.00 & 6.63 & 0.63 \\
\hline Hoosier FAM & hoosierfam & 9803 & 1.00 & 7.00 & 6.81 & 0.30 \\
\hline \multicolumn{7}{|l|}{ Word prevalence } \\
\hline Prevalence & prevalence & 10012 & -0.52 & 2.58 & 2.17 & 0.33 \\
\hline Percentage known & pknown & 10012 & .30 & 1.00 & .98 & .03 \\
\hline Concreteness rating & concrete_m & 9900 & 1.07 & 5.00 & 3.28 & 1.06 \\
\hline Age of acquisition (AoA) & aoa_m & 9392 & 1.89 & 16.38 & 9.06 & 2.66 \\
\hline \multicolumn{7}{|l|}{ Semantic neighborhood density (SND) } \\
\hline Neighbour count (Ncount) & snd_ncount & 9959 & 0 & 9901 & 1927.61 & 2845.60 \\
\hline Average radius of co-occurrence (ARC) & snd_arc & 9959 & .11 & .70 & .50 & .14 \\
\hline \multicolumn{7}{|l|}{ Affective ratings } \\
\hline Valence & aff_val_m & 7612 & 1.30 & 8.53 & 5.18 & 1.29 \\
\hline Arousal & aff_arou_m & 7612 & 1.60 & 7.79 & 4.19 & 0.91 \\
\hline Dominance & aff_dom_m & 7612 & 2.14 & 7.90 & 5.27 & 0.95 \\
\hline
\end{tabular}

For word frequency and contextual diversity, the top and bottom numbers represent the values from the US and UK databases, respectively

\section{Appendix 3 Descriptive statistics of lexical decision measures and token durations}

Table 20 Talker-level estimates

\begin{tabular}{|c|c|c|c|c|c|}
\hline Talker & Database field & Min & Max & $M$ & $S D$ \\
\hline \multicolumn{6}{|l|}{ Words } \\
\hline \multicolumn{6}{|c|}{ Accuracy } \\
\hline $\mathrm{F} 1$ & fl_ldt_acc & .04 & 1.00 & .89 & .15 \\
\hline F2 & f2_ldt_acc & .06 & 1.00 & .91 & .13 \\
\hline F3 & f3_ldt_acc & .04 & 1.00 & .88 & .16 \\
\hline M1 & m1_ldt_acc & .07 & 1.00 & .89 & .15 \\
\hline M2 & m2_ldt_acc & .03 & 1.00 & .89 & .15 \\
\hline M3 & m3_ldt_acc & .03 & 1.00 & .89 & .15 \\
\hline \multicolumn{6}{|c|}{$\underline{\text { Raw reaction time (mean) }}$} \\
\hline $\mathrm{F} 1$ & f1_ldt_rt_m & 604.33 & 1478.50 & 902.53 & 113.25 \\
\hline F2 & f2_ldt_rt_m & 683.03 & 1812.50 & 1018.28 & 121.90 \\
\hline F3 & f3_ldt_rt_m & 608.79 & 1709.60 & 975.03 & 135.84 \\
\hline M1 & m1_ldt_rt_m & 706.63 & 1730.63 & 1070.83 & 137.77 \\
\hline M2 & m2_ldt_rt_m & 667.32 & 1503.69 & 982.87 & 113.84 \\
\hline M3 & m3_ldt_rt_m & 632.19 & 1528.58 & 968.01 & 126.68 \\
\hline \multicolumn{6}{|c|}{$\underline{\mathrm{z} \text {-scored reaction time (mean) }}$} \\
\hline $\mathrm{F} 1$ & f1_ldt_zrt_m & -1.41 & 2.05 & -0.25 & 0.45 \\
\hline F2 & f2_ldt_zrt_m & -1.54 & 1.67 & -0.29 & 0.44 \\
\hline F3 & f3_ldt_zrt_m & -1.59 & 2.33 & -0.23 & 0.52 \\
\hline
\end{tabular}


Table 20 (continued)

\begin{tabular}{|c|c|c|c|c|c|}
\hline Talker & Database field & Min & Max & $M$ & $S D$ \\
\hline M1 & m1_ldt_zrt_m & -1.76 & 1.79 & -0.18 & 0.51 \\
\hline M2 & m2_ldt_zrt_m & -1.50 & 1.59 & -0.19 & 0.46 \\
\hline M3 & m3_ldt_zrt_m & -1.66 & 1.72 & -0.23 & 0.51 \\
\hline \multicolumn{6}{|c|}{$\underline{\mathrm{z} \text {-scored [reaction time minus token duration] (mean) }}$} \\
\hline $\mathrm{F} 1$ & f1_ldt_zrtmdur_m & -1.79 & 2.01 & -0.18 & 0.48 \\
\hline $\mathrm{F} 2$ & f2_ldt_zrtmdur_m & -2.16 & 1.76 & -0.21 & 0.44 \\
\hline F3 & f3_ldt_zrtmdur_m & -1.84 & 2.79 & -0.12 & 0.51 \\
\hline M1 & m1_ldt_zrtmdur_m & -2.18 & 2.18 & -0.15 & 0.51 \\
\hline M2 & m2_ldt_zrtmdur_m & -1.81 & 1.99 & -0.15 & 0.51 \\
\hline M3 & m3 ldt_zrtmdur_m & -2.47 & 2.05 & -0.14 & 0.54 \\
\hline
\end{tabular}

Token duration (ms)

\begin{tabular}{llllll}
\hline F1 & f1_duration & 284.35 & 1328.30 & 689.65 & 143.78 \\
F2 & f2_duration & 423.83 & 1478.50 & 838.39 & 162.60 \\
F3 & f3_duration & 338.59 & 1682.59 & 789.91 & 187.82 \\
M1 & m1_duration & 362.68 & 1899.84 & 937.89 & 202.64 \\
M2 & m2_duration & 344.63 & 1522.29 & 820.57 & 165.11 \\
M3 & m3_duration & 347.21 & 1555.44 & 837.23 & 186.50
\end{tabular}

Nonwords

Accuracy

\begin{tabular}{llllll}
\hline F1 & f1_ldt_acc_nw & .08 & 1.00 & .91 & .10 \\
F2 & f2_ldt_acc_nw & .00 & 1.00 & .90 & .12 \\
F3 & f3_ldt_acc_nw & .07 & 1.00 & .92 & .10 \\
M1 & m1_ldt_acc_nw & .14 & 1.00 & .92 & .10 \\
M2 & m2_ldt_acc_nw & .00 & 1.00 & .92 & .11 \\
M3 & m3_ldt_acc_nw & .10 & 1.00 & .92 & .10
\end{tabular}

$\underline{\text { Raw reaction time (mean) }}$

\begin{tabular}{|c|c|c|c|c|c|}
\hline $\mathrm{F} 1$ & fl_ldt_rt_m_nw & 747.73 & 1452.68 & 996.77 & 88.03 \\
\hline $\mathrm{F} 2$ & f2_ldt_rt_m_nw & 754.00 & 1654.25 & 1145.08 & 100.73 \\
\hline F3 & f3_ldt_rt_m_nw & 758.44 & 1724.00 & 1061.56 & 111.01 \\
\hline M1 & m1_ldt_rt_m_nw & 799.68 & 1617.19 & 1128.62 & 111.50 \\
\hline M2 & m2_ldt_rt_m_nw & 701.00 & 1601.22 & 1041.91 & 89.64 \\
\hline M3 & m3_ldt_rt_m_nw & 748.21 & 1497.67 & 1046.19 & 99.12 \\
\hline \multicolumn{6}{|c|}{$\underline{\mathrm{z} \text {-scored reaction time (mean) }}$} \\
\hline $\mathrm{F} 1$ & f1_ldt_zrt_m_nw & -0.89 & 1.49 & 0.10 & 0.34 \\
\hline $\mathrm{F} 2$ & f2_ldt_zrt_m_nw & -1.14 & 1.67 & 0.14 & 0.37 \\
\hline F3 & f3_ldt_zrt_m_nw & -1.15 & 1.78 & 0.09 & 0.43 \\
\hline M1 & m1_ldt_zrt_m_nw & -1.23 & 1.69 & 0.03 & 0.42 \\
\hline M2 & m2_ldt_zrt_m_nw & -1.40 & 1.56 & 0.03 & 0.37 \\
\hline M3 & m3_1dt_zrt_m_nw & -1.10 & 1.84 & 0.08 & 0.40 \\
\hline \multicolumn{6}{|c|}{$\underline{\mathrm{z} \text {-scored [reaction time minus token duration] (mean) }}$} \\
\hline F1 & f1_ldt_zrtmdur_m_nw & -1.82 & 1.99 & 0.05 & 0.50 \\
\hline $\mathrm{F} 2$ & f2_ldt_zrtmdur_m_nw & -2.14 & 2.51 & 0.08 & 0.48 \\
\hline F3 & f3_ldt_zrtmdur_m_nw & -2.28 & 2.07 & 0.01 & 0.56 \\
\hline M1 & m1_ldt_zrtmdur_m_nw & -2.46 & 2.59 & 0.04 & 0.55 \\
\hline M2 & m2_ldt_zrtmdur_m_nw & -2.15 & 1.86 & 0.02 & 0.55 \\
\hline M3 & $\underset{\text { nw }}{\text { m3_ldt_zrtmdur_m_ }}$ & -2.14 & 1.94 & 0.02 & 0.59 \\
\hline \multicolumn{6}{|c|}{$\underline{\text { Token duration }(\mathrm{ms})}$} \\
\hline F1 & f1_duration_nw & 287.14 & 1313.79 & 718.92 & 141.61 \\
\hline $\mathrm{F} 2$ & f2_duration_nw & 437.35 & 1642.88 & 877.02 & 166.90 \\
\hline
\end{tabular}


Table 20 (continued)

\begin{tabular}{llllll}
\hline Talker & Database field & Min & Max & $M$ & $S D$ \\
\hline F3 & f3_duration_nw & 351.81 & 1889.46 & 840.76 & 196.69 \\
M1 & m1_duration_nw & 334.83 & 1786.03 & 943.79 & 206.02 \\
M2 & m2_duration_nw & 362.47 & 1680.39 & 829.96 & 171.72 \\
M3 & m3_duration_nw & 240.59 & 1595.56 & 869.78 & 188.11 \\
\hline
\end{tabular}

Table 21 Dialect-level estimates

\begin{tabular}{|c|c|c|c|c|c|}
\hline Dialect & Database field & Min & Max & $M$ & $S D$ \\
\hline \multicolumn{6}{|l|}{ Words } \\
\hline \multicolumn{6}{|l|}{ Accuracy } \\
\hline Singapore English & sg_ldt_acc & .09 & 1.00 & .89 & .14 \\
\hline American English & us_ldt_acc & .08 & 1.00 & .90 & .13 \\
\hline British English & uk_ldt_acc & .04 & 1.00 & .89 & .15 \\
\hline \multicolumn{6}{|c|}{$\underline{\text { Raw reaction time (mean) }}$} \\
\hline Singapore English & sg_ldt_rt_m & 686.49 & 1529.88 & 989.30 & 113.44 \\
\hline American English & us_ldt_rt_m & 693.00 & 1529.00 & 1000.04 & 108.87 \\
\hline British English & uk_ldt_rt_m & 630.61 & 1498.71 & 970.47 & 120.65 \\
\hline \multicolumn{6}{|c|}{ z-scored reaction time (mean) } \\
\hline Singapore English & $\overline{\text { sg__ldt_zrt_m }}$ & -1.50 & 1.55 & -0.22 & 0.44 \\
\hline American English & us_ldt_zrt_m & -1.42 & 1.47 & -0.24 & 0.42 \\
\hline British English & uk_ldt_zrt_m & -1.50 & 1.92 & -0.23 & 0.48 \\
\hline \multicolumn{6}{|c|}{$\mathrm{z}$-scored [reaction time minus token duration] (mean) } \\
\hline Singapore English & sg_ldt_zrtmdur_m & -1.63 & 1.40 & -0.17 & 0.46 \\
\hline American English & us_ldt_zrtmdur_m & -1.69 & 1.51 & -0.18 & 0.43 \\
\hline British English & uk_ldt_zrtmdur_m & -1.88 & 2.42 & -0.13 & 0.49 \\
\hline \multicolumn{6}{|l|}{ Token duration (ms) } \\
\hline Singapore English & sg_duration & 362.22 & 1523.72 & 813.77 & 163.95 \\
\hline American English & us_duration & 384.23 & 1475.33 & 829.48 & 151.48 \\
\hline British English & uk_duration & 368.12 & 1559.24 & 813.57 & 176.61 \\
\hline \multicolumn{6}{|l|}{ Nonwords } \\
\hline \multicolumn{6}{|l|}{ Accuracy } \\
\hline Singapore English & sg_ldt_acc_nw & .26 & 1.00 & .88 & .10 \\
\hline American English & us_ldt_acc_nw & .12 & 1.00 & .91 & .10 \\
\hline British English & uk_ldt_acc_nw & .16 & 1.00 & .88 & .10 \\
\hline \multicolumn{6}{|c|}{ Raw reaction time (mean) } \\
\hline Singapore English & sg_ldt_rt_m_nw & 813.37 & 1542.55 & 1066.19 & 86.11 \\
\hline American English & us_ldt_rt_m_nw & 806.63 & 1528.48 & 1091.96 & 82.94 \\
\hline British English & uk_ldt_rt_m_nw & 801.86 & 1543.70 & 1053.44 & 93.51 \\
\hline \multicolumn{6}{|c|}{$\underline{\text { z-scored reaction time (mean) }}$} \\
\hline Singapore English & $\overline{\mathrm{sg}}$ _ldt_zrt_m_nw & -0.90 & 1.57 & 0.06 & 0.34 \\
\hline American English & us_ldt_zrt_m_nw & -0.99 & 1.42 & 0.08 & 0.33 \\
\hline British English & uk_ldt_zrt_m_nw & -0.93 & 1.60 & 0.08 & 0.37 \\
\hline \multicolumn{6}{|c|}{ z-scored [reaction time minus token duration] (mean) } \\
\hline Singapore English & sg_ldt_zrtmdur_m_nw & -1.81 & 2.02 & 0.04 & 0.49 \\
\hline American English & us_ldt_zrtmdur_m_nw & -1.75 & 1.64 & 0.05 & 0.47 \\
\hline British English & uk_ldt_zrtmdur_m_nw & -2.00 & 1.94 & 0.01 & 0.54 \\
\hline \multicolumn{6}{|l|}{ Token duration (ms) } \\
\hline Singapore English & sg_duration_nw & 394.52 & 1524.10 & 831.35 & 164.17 \\
\hline American English & us_duration_nw & 428.19 & 1661.63 & 853.49 & 156.79 \\
\hline British English & uk_duration_nw & 379.89 & 1639.09 & 855.27 & 181.06 \\
\hline
\end{tabular}

Dialect token duration estimates is the average of the male and female tokens 


\section{Appendix 4. Other lists in the downloads section of the website}

Figure 12 shows the homophones for American and British English in Excel format. Some words have the same homophones in both dialects, e.g. altar is a word in the AELP database, and the corresponding homophone for both dialects is alter. The talker ID columns indicate the number of responses recorded for each homophone in the WordID sessions for each talker. Some words have a homophone in one dialect but not the other. For example, aunt is a homophone for ant in American but not British English. This list is useful for users who need to estimate what homophone is likely to be perceived by listeners for a particular target word.
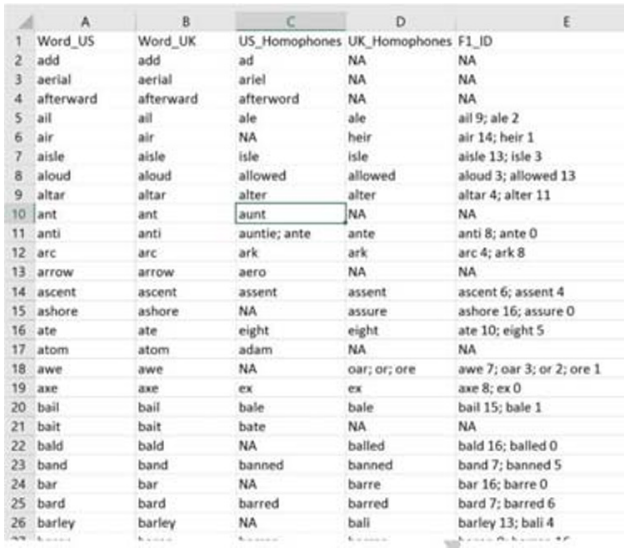

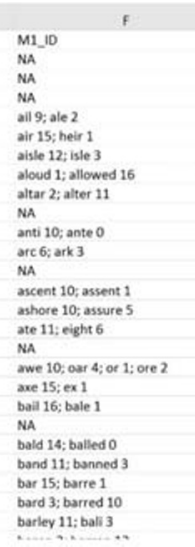
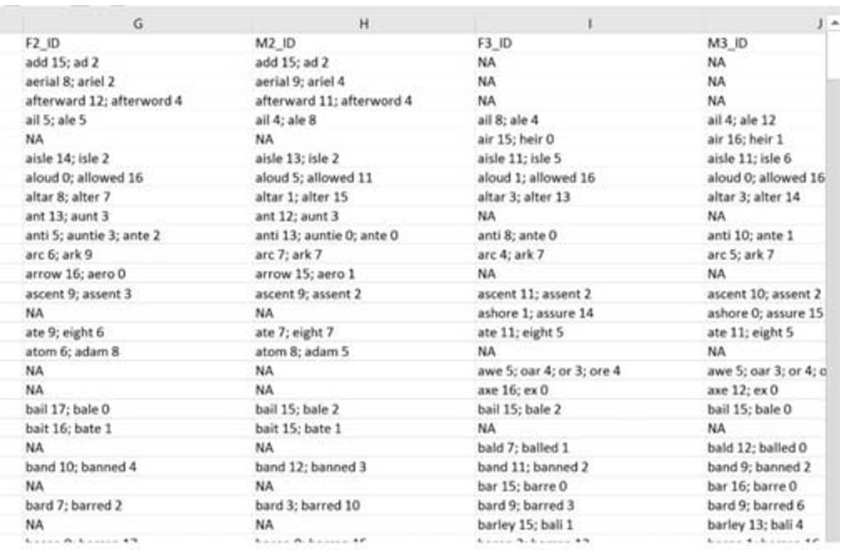

Fig. 12 List of homophones

Table 22 summarizes the participant characteristic fields and value labels for the ALD megastudy.

Table 22 Participant characteristics for auditory lexical decision megastudy

\begin{tabular}{lll}
\hline Variable Name & Description & Values \\
\hline Gender & & 1 Male; 2 Female \\
Hand & Handedness & 1 Left; 2 Right; 3 Ambidextrous \\
Ghent ${ }^{1}$ & Ghent vocabulary score & \\
Vocab & Vocabulary score from Levy et al. (2017) & \\
Spelling & Spelling score from Burt \& Tate (2002) & \\
Country/Region_x ${ }^{2}$ & Countries or regions lived in & \\
& & 1 Singapore; 2 Australia; 3 China; 4 England; 5 Germany; \\
& & 6 Hong Kong SAR; 7 India; 8 Indonesia; 9 Malaysia; \\
CRx_Age & 10 Myanmar; 11 Taiwan; 12 USA; 13 Burma; 14 Canada; \\
CRx_Year & Age when started living in country/region & 15 Laos; 16 Philippines \\
L1 & Number of years lived in country/region & \\
L2 & First language & 1 English; 2 Chinese; 3 Malay; 4 Tamil; 5 Chinese dialect; \\
L3 & Second language & 6 Indian dialect; 7 Japanese; 8 Korean; 9 German; 10 French; \\
L4 & Third language & 11 Spanish; 12 Russian; 13 Thai; 14 Vietnamese; 15 Bahasa \\
& Fourth language & Indonesia; 16 Khmer; 17 Arabic; 18 Tagalog; 19 Swedish; \\
Lx_AOA & 20 Javanese; 21 Burmese \\
Lx_L & Age of acquisition & \\
Lx_R & Listening proficiency (0-7) & Self-rated higher values represent greater proficiency \\
Lx_S & Reading proficiency (0-7) & \\
Lx_W & Speaking proficiency (0-7) & \\
\hline
\end{tabular}

1. To screen out non-native English speakers, we had asked prospective participants to report their scores for the Ghent University Word Test at http:// vocabulary.ugent.be/ (retrieved 24 October 2019), adopting a minimum criterion of $40 \%$ to take part in the Word recognition phases. See also Brysbaert, et al. (2019).

2. "x" represents a number. For example, if the participant lived in more than one region/country, CR1_Age and CR2_Age would represent the age he or she started living in those countries/regions. Likewise, if they know more than one language, L1_L and L2_L would represent their self-reported listening proficiency for the first and second languages, respectively. 


\section{References}

Andrews, S. (1997). The effect of orthographic similarity on lexical retrieval: Resolving neighbourhood conflicts. Psychonomic Bulletin \& Review, 4, 439-461.

Balota, D. A., Cortese, M. J., Sergent-Marshall, S., Spieler, D. H., \& Yap, M. J. (2004). Visual word recognition of single-syllable words. Journal of Experimental Psychology: General, 133, 283-316.

Balota, D., Yap, M. J., \& Cortese, M. J. (2006). Visual word recognition: The journey from features to meaning (A travel update). In M. Traxler \& M. A. Gernsbacher (Eds.) Handbook of psycholinguistics (2nd) (pp. 285-375). Amsterdam: Academic Press.

Balota, D. A., Yap, M. J., Cortese, M. J., Hutchison, K. A., Kessler, B., Loftis, B., ... , Treiman, R. (2007). The English Lexicon Project. Behaviour Research Methods, 39, 445-459.

Balota, D. A., Yap, M. J., Hutchison, K.A., \& Cortese, M. J. (2012). Megastudies: What do millions (or so) of trials tell us about lexical processing? In James S. Adelman (Ed). Visual word recognition (pp. 90-115). Hove: Psychology Press.

Bates, D., Maechler, M., Bolker, M., \& Walker, S. (2015). Fitting linear mixed-effects models using lme4. Journal of Statistical Software, 67, 1-48. doi:https://doi.org/10.18637/jss.v067.i01

The British National Corpus, version 3 (BNC XML Edition) (2007). Distributed by Bodleian Libraries, University of Oxford, on behalf of the BNC Consortium. Retrieved from: http://www.natcorp.ox.ac. uk/

Brysbaert, M., Mandera, P., McCormick, S. F., \& Keuleers, E. (2019). Word prevalence norms for 62,000 English lemmas. Behavior Research Methods, 51, 467-479.

Brysbaert, M., \& New, B. (2009). Moving beyond Kucera and Francis: A critical evaluation of current word frequency norms and the introduction of a new and improved word frequency measure for American English. Behaviour Research Methods, 41, 977-990.

Brysbaert, M., Warriner, A.B., \& Kuperman, V. (2014). Concreteness ratings for 40 thousand generally known English word lemmas. Behaviour Research Methods, 46, 904-911.

Burt, J. S., \& Tate, H. (2002). Does a reading lexicon provide orthographic representations for spelling? Journal of Memory and Language, $46(3), 518-543$.

Cortese, M. J., \& Fugett, A. (2004). Imageability ratings for 3,000 monosyllabic words. Behaviour Research Methods, Instruments, \& Computers, 36, 384-387.

Courrieu, P., \& Rey, A. (2011). Missing data imputation and corrected statistics for large-scale behavioral databases. Behavior Research Methods, 43, 310-330. doi:https://doi.org/10.3758/s13428-0110071-2.

Crowder, R. G. (1971). The sound of vowels and consonants in immediate memory. Journal of Verbal Learning and Verbal Behavior, 10, $587-596$.

Crowder, R. G., \& Morton, J. (1969). Precategorical acoustic storage (PAS). Perception \& Psychophysics, 5, 365-373.

Cutler, A. (1981). Making up materials is a confounded nuisance: or will we be able to run any psycholinguistic experiments at all in 1990 ? Cognition, 10, 65-70.

Dahan, D., \& Magnuson, J. S. (2006). Spoken word recognition. In M. Traxler \& M. A. Gernsbacher (Eds.) Handbook of psycholinguistics (2nd) (pp. 249-283). Amsterdam: Academic Press.

Deterding, D. (2007). Singapore English. Edinburgh: Edinburgh University Press.

Ernestus, M., \& Cutler, A. (2015). BALDEY: A database of auditory lexical decisions. Quarterly Journal of Experimental Psychology, 68, 1469-1488.

Faust, M. E., Balota, D. A., Spieler, D. H., \& Ferraro, F. R. (1999). Individual differences in information-processing rate and amount:
Implications for group differences in response latency. Psychological Bulletin, 125, 777-799.

Ferrand, L., Méot, A., Spinelli, E., New, B., Pallier, C., Bonin, P., ..., Grainger, J. (2018). MEGALEX: A megastudy of visual and auditory word recognition. Behaviour Research Methods, 50, 12851307.

Garofolo, J. S., Lamel, L. F., Fisher, W. M., Fiscus, J. G., Pallett, D. S., Dahlgren, N. L., \& Zue, V. (1993). TIMIT Acoustic-Phonetic Continuous Speech Corpus LDC93S1. Philadelphia: Linguistic Data Consortium.

Gernsbacher, M. A. (1984). Resolving 20 years of inconsistent interactions between lexical familiarity and orthography, concreteness, and polysemy. Journal of Experimental Psychology: General, 113, 256281.

Goh, W. D. (2005). Talker variability and recognition memory: Instancespecific and voice-specific effects. Journal of Experimental Psychology: Learning, Memory, and Cognition, 31, 40-53.

Goh, W. D., Suárez, L., Yap, M. J., \& Tan, S. H. (2009). Distributional analyses in auditory lexical decision: Neighbourhood density and word frequency effects. Psychonomic Bulletin \& Review, 16, 882887.

Goh, W. D., Yap, M. J., Lau, M. C., Ng, M. M. R., \& Tan, L. C. (2016). Semantic richness effects in spoken word recognition: A lexical decision and semantic categorisation megastudy. Frontiers in Psychology, 7, 976.

Goldinger, S. D. (1996a). Auditory lexical decision. Language and Cognitive Processes, 11, 559-567.

Goldinger, S. D. (1996b). Words and voices: Episodic traces in spoken word identification and recognition memory. Journal of Experimental Psychology: Learning, Memory, and Cognition, 22, 1166-1183.

Goldinger, S. D. (1998). Echoes of echoes? An episodic theory of lexical access. Psychological Review, 105, 252-279.

House, A. S., Williams, C. E., Hecker, M. H. L., \& Kryter, K. D. (1965). Articulation-testing methods: Consonantal differentiation with a closed-response set. Journal of the Acoustical Society of America, $37,158-66$.

IEEE. (1969). IEEE recommended practice for speech quality measurements (IEEE Report No. 297).

Johnson, N. F., \& Pugh, K. R. (1994). A cohort model of visual word recognition. Cognitive Psychology, 26, 240-346.

Keuleers, E., \& Brysbaert, M. (2010). Wuggy: A multilingual pseudoword generator. Behavior Research Methods, 42, 627-633.

Keuleers, E., Lacey, P., Rastle, K., \& Brysbaert, M. (2012). The British Lexicon Project: lexical decision data for 28,730 monosyllabic and disyllabic English words. Behavior Research Methods, 44, 287304.

Kreuz, R. J. (1987). The subjective familiarity of English homophones. Memory \& Cognition, 15, 154-168.

Kuperman, V., Stadthagen-Gonzalez, H., \& Brysbaert, M. (2012). Ageof-acquisition ratings for 30 thousand English words. Behaviour Research Methods, 44, 978-990.

Kuznetsova, A., Brockhoff, P. B., \& Christensen, R. H. B. (2016). ImerTest: Tests for Random and Fixed Effects for Linear Mixed Effect Models (lmer Objects of Lme4 Package): R Package Version 2.0-6. Available online at: http://CRAN.R-project.org/ package $=$ lmerTest

Leimgruber, J. R. E. (2011). Singapore English. Language and Linguistics Compass, 5, 47-62.

Levy, J., Bullinaria, J., \& McCormick, S. (2017). Semantic vector evaluation and human performance on a new vocabulary MCQ test. In G. Gunzelmann, A. Howes, T. Tenbrink, \& E. Davelaar (Eds.), Proceedings of the 39th Annual Conference of the Cognitive Science Society (pp. 2549-2554). Austin, TX: Cognitive Science Society. 
Lim, L. C. L., \& Goh, W. D. (2019). False recognition modality effects in short-term memory: Reversing the auditory advantage. Cognition, 193, https://doi.org/10.1016/j.cognition.2019.104008

Logan, J. S., Lively, S. E., \& Pisoni, D. B. (1991). Training Japanese listeners to identify English /r/ and /1/: A first report. Journal of the Acoustical Society of America, 89, 874-886.

Luce, P. A. (1986). A computational analysis of uniqueness points in auditory word recognition. Perception \& Psychophysics, 39, 155158

Luce, P. A., \& Pisoni, D. B. (1998). Recognising spoken words: The neighbourhood -activation model. Ear \& Hearing, 19, 1-36.

Makino, S., Abe, M., \& Kido, K. (1988). An isolated spoken word database using CD-ROMs. Journal of the Acoustical Society of America, $84, \mathrm{~S} 218$.

Marslen-Wilson, W., \& Welsh, A. (1978). Processing interactions and lexical access during word recognition in continuous speech. Cognitive Psychology, 10, 29-63.

McRae, K., Cree, G., Seidenberg, M., \& McNorgan, C. (2005). Semantic feature production norms for a large set of living and nonliving things. Behaviour Research Methods, Instruments, \& Computers, $37,547-559$

Nygaard, L. C., Sommers, M. S., \& Pisoni, D. B. (1994). Speech perception as a talker-contingent process. Psychological Science, 5, 42-46.

Nusbaum, H. C., Pisoni, D. B., \& Davis, C. K. (1984). Sizing up the Hoosier Mental Lexicon: Measuring the familiarity of 20,000 words (Research on Speech Perception Progress Report No. 10). Bloomington: Speech Research Laboratory, Department of Psychology, Indiana University.

Olszewska, J. M., Reuter-Lorenz, P. A., Munier, E., \& Bendler, S. A. (2015). Misremembering what you see or hear: Dissociable effects of modality on short- and long-term false recognition. Journal of Experimental Psychology: Learning, Memory and Cognition, 41, 1316-1325.

Osgood, C. E., Suci, G. J., \& Tannenbaum, P. H. (1957). The measurement of meaning. Urbana, IL: University of Illinois Press.

Oxford Dictionaries. (2019). Oxford University Press: Oxford, United Kingdom. Retrieved from: https://www.lexico.com

Peereman, R., \& Content, A. (1997). Orthographic and phonological neighbourhoods in naming: Not all neighbours are equally influential in orthographic space. Journal of Memory \& Language, 37, $382-410$.

Penney, C. G. (1989). Modality effects and the structure of short-term verbal memory. Memory \& Cognition, 17, 398-422.

Pexman, P. M. (2012). Meaning-based influences on visual word recognition. In J. S. Adelman (Ed.), Visual Word Recognition Volume 2 (pp. 24-43). Hove: Psychology Press.

Pisoni, D. B. (1996). Word identification in noise. Language and Cognitive Processes, 11, 681-688.

Pisoni, D. B., \& Lively, S. E. (1995). Variability and invariance in speech perception: A new look at some old problems in perceptual learning. In W. Strange (Ed.), Speech perception and linguistic experience (pp. 433-459). Baltimore: York Press.

R Core Team (2019). R: A language and environment for statistical computing [Computer software]. Vienna, Austria: R Foundation for Statistical Computing. https://www.R-project.org/

Roediger, H. L., Watson, J. M., McDermott, K. B., \& Gallo, D. A. (2001). Factors that determine false recall: A multiple regression analysis. Psychonomic Bulletin \& Review, 8, 385-407.
Rosenzweig, M. R., \& Postman, L. (1957). Intelligibility as a function of frequency of usage. Journal of Experimental Psychology, 54, 412422.

Sajin, S. M., \& Connine, C. M. (2014). Semantic richness: The role of semantic features in processing spoken words. Journal of Memory and Language, 70, 13-35.

Shaoul, C., \& Westbury, C. (2010). Exploring lexical co-occurrence space using HiDEx. Behaviour Research Methods, 42, 393-413.

Schneider, W., Eschman, A., \& Zuccolotto, A. (2002). E-Prime user's guide. Pittsburgh: Psychology Software Tools Inc.

Schneider, W., Eschman, A., \& Zuccolotto, A. (2012). E-Prime 2.0 user's guide. Pittsburgh: Psychology Software Tools Inc.

Schock, J., Cortese, M. J., \& Khanna, M. M. (2012). Imageability estimates for 3,000 disyllabic words. Behaviour Research Methods, 44, 374-379.

Shipley, W.C. (1940). A self-administering scale for measuring intellectual impairment and deterioration. The Journal of Psychology, 9, 371-377.

Singh, L. (2008). Influences of high and low variability on infant word recognition. Cognition, 106, 833-870.

Sommers, M. S., \& Lewis, B. P. (1999). Who really lives next door: Creating false memories with phonological neighbours. Journal of Memory and Language, 40, 83-108.

Taft, M., \& Hambly, G. (1986). Exploring the Cohort Model of spoken word recognition. Cognition, 22, 259-282.

Tay, M. W. J., \& Gupta, A. F. (1983). Towards a description of Standard Singapore English. In R. B. Noss (ed.), Varieties of English in Southeast Asia (pp. 173-189). Singapore: SEAMEO Regional Language Centre.

Treisman, M. (1978). Space or lexicon? The word frequency effect and the error response frequency effect. Journal of Verbal Learning and Verbal Behavior, 17, 37-59.

Tucker, B. V., Brenner, D., Danielson, D. K., Kelley, M. C., Nenadić, F., \& Sims, M. (2019). The Massive Auditory Lexical Decision (MALD) database. Behaviour Research Methods, 51, 1187-1204.

Vitevitch, M. S. (2002). Influence of onset density on spoken-word recognition. Journal of Experimental Psychology: Human Perception and Performance, 28, 270-278.

Vitevitch, M. S. (2007). The spread of the phonological neighborhood influences spoken word recognition. Memory \& Cognition, 35, 166 175.

Vitevitch, M. S. (2008). What can graph theory tell us about word learning and lexical retrieval? Journal of Speech, Language, and Hearing Research, 51, 408-422.

Vitevitch, M. S., \& Luce, P. A. (2004). A web-based interface to calculate phonotactic probability for words and nonwords in English. Behavior Research Methods, Instruments, and Computers, 36, 481-487.

Warriner, A. B., Kuperman, V., \& Brysbaert, M. (2013). Norms of valence, arousal, and dominance for 13,915 English lemmas. Behaviour Research Methods, 45, 1191-1207.

Watts, D. J., \& Strogatz, S. H. (1998). Collective dynamics of "smallworld" networks. Nature, 393, 409-410.

Yarkoni, T., Balota, D., \& Yap, M. J. (2008). Moving beyond Coltheart's $\mathrm{N}$ : a new measure of orthographic similarity. Psychonomic Bulletin \& Review, 15, 971-979.

Publisher's note Springer Nature remains neutral with regard to jurisdictional claims in published maps and institutional affiliations. 